Argonne

\title{
Multi-Physics Simulations of Heat Pipe Micro Reactor
}

Nuclear Science and Engineering Division 


\begin{abstract}
About Argonne National Laboratory
Argonne is a U.S. Department of Energy laboratory managed by UChicago Argonne, LLC under contract DE-AC02-06CH11357. The Laboratory's main facility is outside Chicago, at 9700 South Cass Avenue, Argonne, Illinois 60439. For information about Argonne and its pioneering science and technology programs, see www.anl.gov.
\end{abstract}

\title{
DOCUMENT AVAILABILITY
}

Online Access: U.S. Department of Energy (DOE) reports produced after 1991 and a growing number of pre-1991 documents are available free at OSTI.GOV (http://www.osti.gov/), a service of the U.S. Dept. of Energy's Office of Scientific and Technical Information

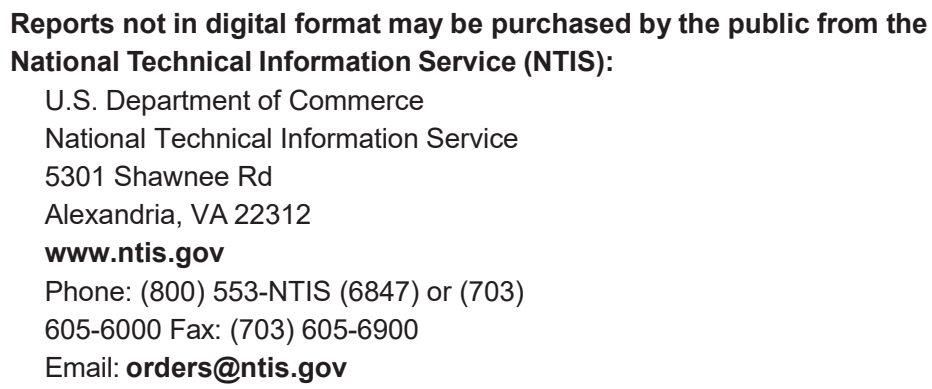

Reports not in digital format are available to DOE and DOE contractors from the Office of Scientific and Technical Information (OSTI):

U.S. Department of Energy

Office of Scientific and Technical Information

P.O. Box 62

Oak Ridge, TN 37831-0062

www.osti.gov

Phone: (865) 576-8401

Fax: (865) 576-5728

Email: reports@osti.gov

\section{Disclaimer}

This report was prepared as an account of work sponsored by an agency of the United States Government. Neither the United States Government nor any agency thereof, nor UChicago Argonne, LLC, nor any of their employees or officers, makes any warranty, express or implied, or assumes any legal liability or responsibility for the accuracy, completeness, or usefulness of any information, apparatus, product, or process disclosed, or represents that its use would not infringe privately owned rights. Reference herein to any specific commercial product, process, or service by trade name, trademark, manufacturer, or otherwise, does not necessarily constitute or imply its endorsement, recommendation, or favoring by the United States Government or any agency thereof. The views and opinions of document authors expressed herein do not necessarily state or reflect those of the United States Government or any agency thereof, Argonne National Laboratory, or UChicago Argonne, LLC. 
ANL-NSE-19/25

\section{Multi-Physics Simulations of Heat Pipe Micro Reactor}

prepared by

G. $\mathrm{Hu}^{\mathrm{a}}$, R. Hu${ }^{\mathrm{a}}$, J. M. Kelly ${ }^{\mathrm{b}}$ J. Ortensic, ${ }^{a}$ Nuclear Science and Engineering Division, Argonne National Laboratory

${ }^{\mathrm{b}}$ Nuclear Regulatory Commission

Idaho National Laboratory

September 2019 



\section{EXECUTIVE SUMMARY}

System Analysis Module (SAM) is under development at Argonne National Laboratory as a modern system-level modeling and simulation tool for advanced non-light water reactor safety analyses. It utilizes the object-oriented application framework MOOSE to leverage the modern software environment and advanced numerical methods. The capabilities of SAM are being extended to enable the transient modeling, analysis, and design of various advanced nuclear reactor systems. This report presents the development of new capabilities for modeling the heat pipe type reactor systems.

The need for power at remote locations away from a reliable electrical grid is an important niche for nuclear energy. Heat pipe-cooled fast-spectrum nuclear reactors are well suited for these applications. The key feature of the heat pipe reactors is the use of heat pipes for heat removal from the reactor core. The heat pipe makes use of the phase change of the working fluid and transports a large amount of heat from the evaporator to the condensation end with very small temperature drops. In contrast to the traditional nuclear reactor system that makes use of pumped loop for extracting the thermal power, the heat pipe reactors make use of hundreds of heat pipes for removing the thermal power (including the decay heat) passively. This could potentially significantly improve the reliability and safety of the reactor systems. The essential part in the analysis of a heat pipe type reactor is the modeling of heat transport inside the heat pipe. The capability of SAM was extended to enable the modeling of the conventional heat pipe.

The full suite of non-LWR codes for confirmatory analysis at NRC is known as the Comprehensive Reactor Analysis Bundle (CRAB). It makes use of existing NRC codes, and integrates them with several codes developed through the DOE-NE's Nuclear Energy Advanced Modeling and Simulation (NEAMS) program. In this report, the heat pipe micro reactor is simulated using three submodules under CRAB. The MAMMOTH module is used to simulate the reactor kinetics behavior of the micro reactor; the SAM module is used to simulate the heat conduction in the reactor core and heat removal through the heat pipe heat exchangers and Reactor Cavity Cooling System (RCCS); and the MOOSE Tensor Mechanics module is used to simulate the thermal expansion of the reactor cores. The different sub-models are coupled together using MOOSE's MultiApp system and executed using the BlueCrab application. The new capability has been demonstrated by a steady-state operation analysis, a failure of a single central heat pipe transient analysis, and a loss of heat sink transient analysis. The fully coupled model is shown to work well. 


\section{Table of Contents}

EXECUTIVE SUMMARY ...........................................................................................

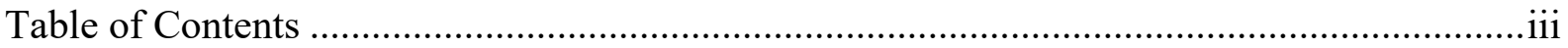

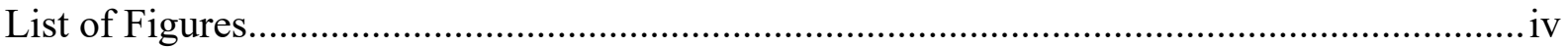

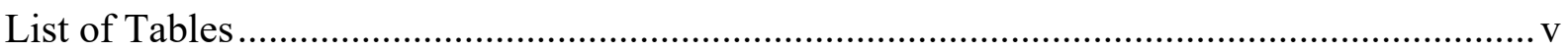

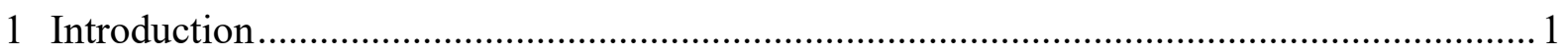

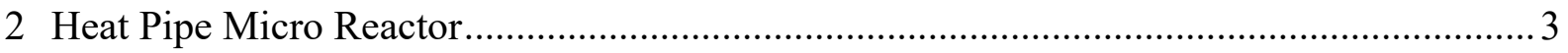

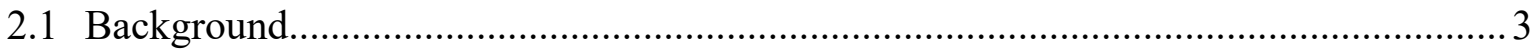

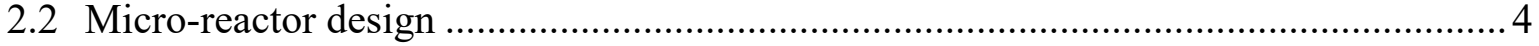

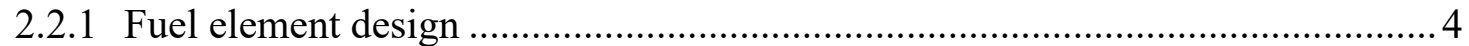

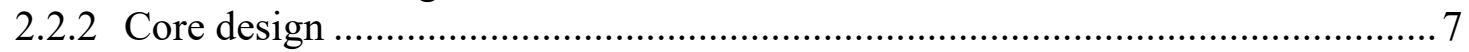

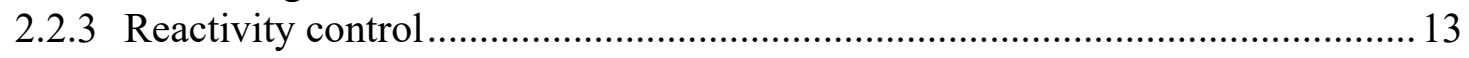

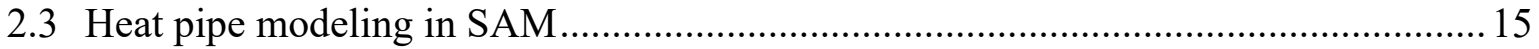

3 Multi-Physics Coupling Methodology ………………................................................. 18

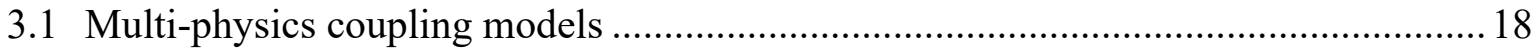

3.2 Modeling of reactor kinetics with MAMMOTH ...................................................... 19

3.2.1 Cross-section and SPH factor generation ...................................................22

3.2.2 MAMMOTH 3D mesh ...........................................................................23

3.2.3 Reactivity feedback effects ......................................................................25

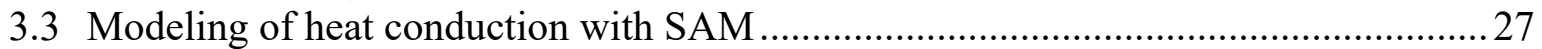

3.4 Modeling of secondary heat exchanger with SAM …………………………...........2.

3.5 Modeling of reactor cavity cooling system (RCCS) with SAM....................................30

3.6 Modeling of axial expansion with Tensor Mechanics....................................................31

3.7 Modeling of radial expansion with Tensor Mechanics ……………………………........ 31

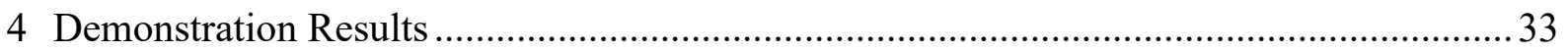

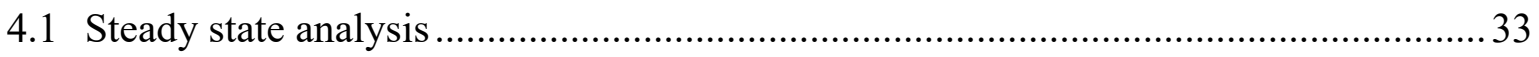

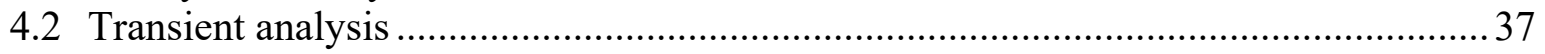

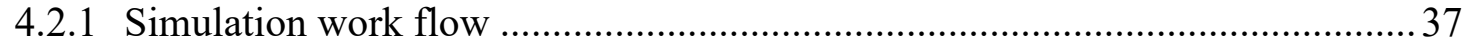

4.2.2 Null transient: effect of initial negative reactivity ………….........................38

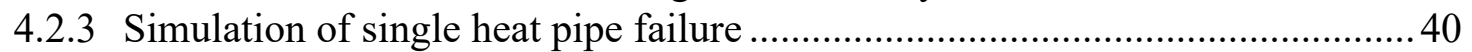

4.2.4 Simulation of unprotected loss of heat sink event ......................................... 43

4.2.5 Discussion on current issues ......................................................................... 46

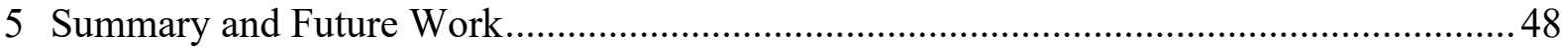

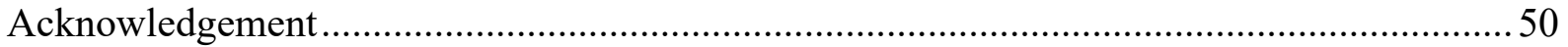

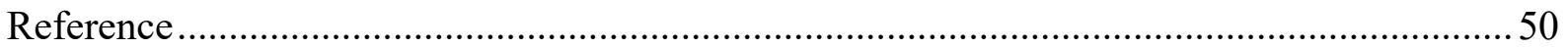




\section{LIST OF FIGURES}

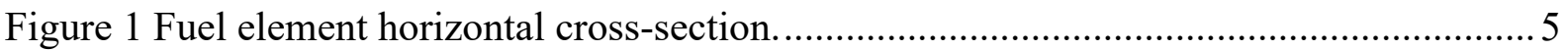

Figure 2 Axial cross-section of modeled portion of fuel element. ............................................. 6

Figure 3 Cross-section of fuel element micro-reactor core................................................... 9

Figure 4 Serpent mesh plot denoting radial power distribution (hot color map) and thermal flux distribution (cold color map) ....................................................................... 10

Figure 5 Fuel element radial power distribution $(\mathrm{kW})$........................................................ 11

Figure 6 Axial cutaway of Serpent mesh plot depicting fission power (hot color map) and

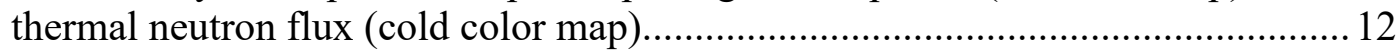

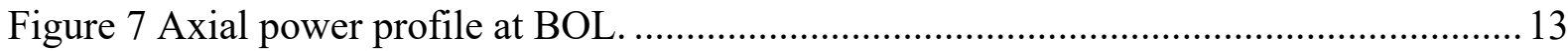

Figure $8 \mathrm{~A}$ conventional heat pipe showing the principle of operation and circulation of the working fluid ............................................................................................ 15

Figure 9 A conventional heat pipe in axsymmetric coordinate .............................................. 16

Figure 10 Heat pipe steady-state verification results ......................................................... 16

Figure 11 Schematic of the multi-physics coupling method for heat pipe micro reactors....... 19

Figure 12 Analysis workflow for cross-section and SPH factor generation. ...........................21

Figure 13 MAMMOTH homogenized finite element mesh...................................................23

Figure 14 Portion of MAMMOTH mesh for which SPH factors are calculated......................22

Figure 15 The heat pipe micor reactor 3D heat conduction model. Left: top view; Right: front

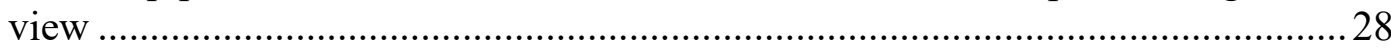

Figure 16 3D mesh for the heat conduction in the reactor core. Left: support plate, hex can, fuel, lower/upper reflector, central control space. Right: side reflector and reactor

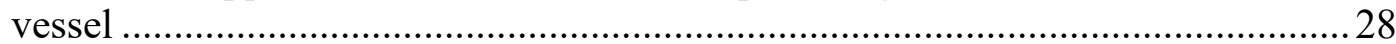

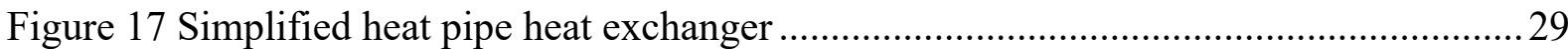

Figure 18 Simplified model of secondary heat exchanger in SAM ...........................................30

Figure 19 Simplified model of reactor cavity cooling system in SAM......................................31

Figure 20 Simplified model for axial expansion of fuel cell in Tensor Mechanics ...................31

Figure 21 Simplified model for reactor radial expansion in Tensor Mechanics .........................32

Figure 22 Steady state solid temperature profile. Horizontal cut view. ......................................34

Figure 23 Steady state solid temperature profile. Vertical cut view. ........................................34

Figure 24 Distribution of average fuel temperature at different fuel cells ................................35

Figure 25 Distribution of heat removal rate through different heat pipes .................................35

Figure 26 Distribution of fuel axial expansion at different fuel cells.......................................36

Figure 27 Radial expansion in the plate. Left: $\mathrm{x}$-displacement along the $\mathrm{x}$-axis; Right: $\mathrm{y}$ -

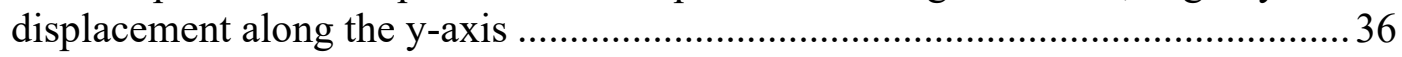

Figure 28 Transient analysis work flow and quantity of interest .............................................38

Figure 29 History of total power in the null transient simulation ............................................38

Figure 30 History of average fuel temperature in the null transient simulation.......................39

Figure 31 History of heat pipe heat removal rate in the null transient simulation ....................39

Figure 32 IDs of heat pipes and fuel cells near the center of the reactor core .........................4 40

Figure 33 Transient heat pipe heat removal rate in HP1, HP2, HP8, and HP9 ........................4

Figure 34 Transient average fuel temperature in FC1, FC2, FC8, and FC9 …….................... 41

Figure 35 Transient total power with the failure of a single heat pipe ....................................4 42

Figure 36 Heat pipe heat removal rate at the start (left, $t=200 \mathrm{~s}$ ) and end (right, $\mathrm{t}=500 \mathrm{~s}$ ) of single heat pipe failure transient........................................................................... 42 
Figure 37 Average fuel temperature at the start (left, $t=200 \mathrm{~s}$ ) and end (right, $\mathrm{t}=500 \mathrm{~s}$ ) of single heat pipe failure transient

Figure 38 Transient reactor power and heat removal rate .................................................... 44

Figure 39 Transient average solid temperature of different blocks........................................ 44

Figure 40 Transient heat pipe removal rate at different time following the loss of heat sink.. 45

Figure 41 Transient fuel temperature following the loss of heat sink .....................................46

\section{LIST OF TABLES}

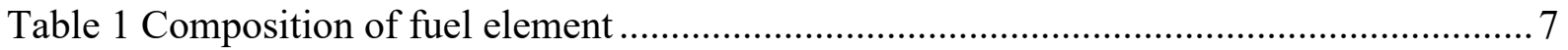

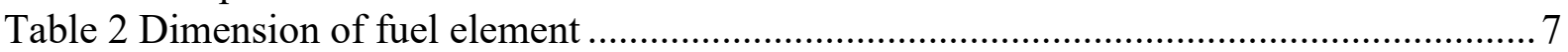

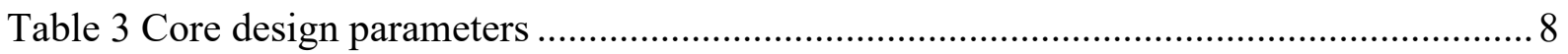

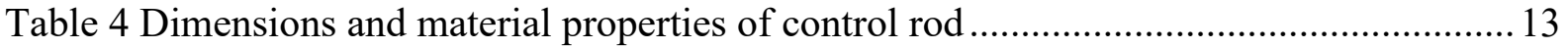

Table 5 Dimensions and material properties of control drum................................................ 14

Table 6 Reference plane design reactivity control parameters................................................... 14

Table 7 Comparison of 6-group and 5-group energy structures...............................................22

Table 8 Decay constants and effective delayed neutron fractions ..........................................22

Table 9 Meshing parameters for the MAMMOTH model .....................................................2 24

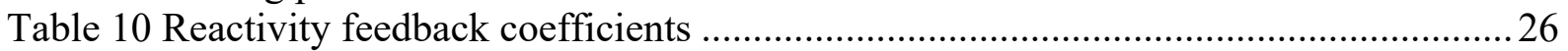

Table 11 Comparison of Serpent2 and MAMMOTH results ..............................................2.

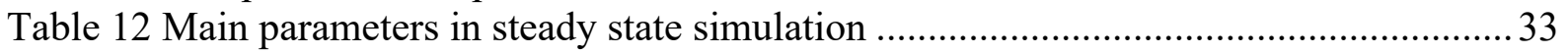





\section{Introduction}

Over the past few years, the rapidly rising interest in advanced nuclear reactor technology has led to an increased need for the developments and applications of advanced computational tools for modeling and simulation. System Analysis Module (SAM) is being developed at Argonne National Laboratory as a modern system-level modeling and simulation tool for advanced nonlight water reactor safety analyses [Hu 2017, $\mathrm{Hu}$ et al. 2019a]. It utilizes the object-oriented application framework MOOSE [Gaston, 2009] to leverage the modern software environment and advanced numerical methods [Balay, 2018]. The capabilities of SAM are being extended to enable the transient modeling, analysis, and design of various advanced nuclear reactor systems.

The need for power at remote locations away from a reliable electrical grid is an important niche for nuclear energy. Heat pipe-cooled fast-spectrum nuclear reactors are well suited for these applications [McClure et al. 2015]. The key part of the heat pipe reactors is the heat pipes used to cool the reactor core. The heat pipe makes use of the phase change of the working fluid and transport a large amount of heat from the evaporator to the condensation end with very small temperature drops [Faghri, 1995]. In contrast to the traditional nuclear reactor system that makes use of pumped loop for extracting the thermal power, the heat pipes reactors make use of hundreds of heat pipes for removing the thermal power (including the decay heat) passively. The reliability and safety of the reactor system can be significantly improved.

Technical issues associated with simulation of heat pipe cooled designs are quite unique. Fluid within the heat pipe (normally alkali metals or alloys at sub-atmospheric pressure) evaporates at the heat source and condenses at the heat sink causing the heat pipe to act like a superconductor. An important neutronic issue is the radial and axial expansion of the core and its supporting structures. Radial expansion increases the leakage of fast neutrons from the core, and this leakage is expected to represent the largest component of negative reactivity. The heat pipes also represent a path for neutron leakage from the core, and this effect must also be accounted for. Heat transport in the reactor core and supporting structures and components are also important in heat removal during many accident scenarios such as a loss of heat removal to the secondary side which renders the heat pipe ineffective. Heat must then be conducted through the various structures to the vessel wall where heat is then removed by a Reactor Cavity Cooling System (RCCS) or by natural convection to the ambient.

The essential part in the analysis of a heat pipe type reactor is the modeling of heat transport in the heat pipe. The capability of SAM was extended in a prior work to enable the modeling of the conventional heat pipe [Hu et al. 2019b]. The modeling approach assumes that heat pipe vapor core can be seen as a superconductor of extremely high thermal conductivity. The modeling approach in SAM was shown to work well [Hu et al. 2019b].

The full suite of non-LWR codes for confirmatory analysis at NRC is known as the Comprehensive Reactor Analysis Bundle (CRAB). It makes use of existing NRC codes, and integrates them with several codes developed through the DOE-NE's Nuclear Energy Advanced Modeling and Simulation (NEAMS) program. In this report, the new capabilities in SAM together with other modules under CRAB [US NRC, 2019] are demonstrated by modeling and simulation the heat pipe micro reactor in a three-dimensional (3D) fully-coupled method. The heat pipe micro reactor are modeled by 3 modules of CRAB, including MAMMOTH [Wang, 2018], SAM [Hu, 2017], and Tensor Mechanics [Gaston, 2009]. The MAMMOTH module is used to simulate the 
reactor kinetics behavior of the micro reactor; the SAM module is used to simulate the heat conduction in the reactor core and heat removal through the heat pipe heat exchangers and RCCS; and the Tensor Mechanics module in MOOSE is used to simulate the thermal expansion of the reactor cores. The different sub-models are coupled together using MOOSE's MultiApp system and executed using the BlueCrab Application (the executable of the combined CRAB code suite). The coupled multi-physics simulation capability is demonstrated by a steady-state operation analysis, a failure of a single central heat pipe transient analysis, and a loss of secondary flow transient analysis.

This document is structured as follows: Section 2 provides an overview of the design of heat pipe micro reactor and the modeling of heat pipe in SAM; Section 3 presents the details of the submodels of the heat pipe micro reactor. Section 4 describes several multi-physics demonstration simulations of the heat pipe micro reactor using BlueCrab. A brief summary of this work and necessary future work is provided in Section 5. 


\section{Heat Pipe Micro Reactor}

\subsection{Background}

The need for power at remote locations away from a reliable electrical grid is an important niche for nuclear energy [McClure et al. 2015]. Nuclear energy has potential applications at strategic defense locations, theaters of battle, remote communities, and emergency locations. Heatpipe-cooled fast-spectrum nuclear reactors have been identified as a candidate for these applications. Heat pipe reactors are perfectly suited for mobile applications because of their nature. A heat pipe reactor is inherently simpler, smaller, and potentially more reliable than the "traditional" reactors. The key part of the heat pipe reactors is the heat pipes used to cool the reactor core.

The USNRC's plan for the development of an analysis capability for advanced non-Light Water Reactors calls for the generation of "Reference Plant" models for each design. The intent is that the reference plant can be exercised through simulation of normal operation and several hypothetical transients to verify that model and code(s) are ready for confirmatory analysis. As such, the reference plant is intended to approximate, but not be fully representative, of design(s) that may be submitted to the NRC for Design Certification review. The development of just such a reference plant model for a "fuel element" type heat pipe cooled micro-reactor is the focus of this work.

In particular, the heat pipe cooled micro-reactor poses a number of modeling challenges that are substantially different from those of traditional LWRs. Specifically:

- Use of a fast neutron spectrum

- Possible usage of metallic fuel

- Enhanced neutron leakage due to streaming through the heat pipe vapor core

- Large negative reactivity feedback effects due to thermal expansion of both the fuel and the core support plate

- Passive conduction cooldown with vessel cooling system for decay heat removal

Meeting these challenges requires not only an advanced reactor kinetics analysis capability but a fully coupled multi-physics approach involving:

- Reactor Kinetics

- Thermomechanics

- 3D Heat Transfer

- Heat Pipe Modeling

Consequently, the development of this reference plant model provides both a test bench for the multi-app system and data transfer capabilities of MOOSE-based codes, and a means to identify potential code development "gaps". 


\subsection{Micro-reactor design}

It is considered likely that the NRC will receive one or more licensing submittals for heat pipe cooled micro reactors. Two distinct classes of these types of reactors have been discussed: the "monolith" type [McClure et al, 2015] and the "fuel element" type [Sterbentz et al, 2018]. This report details the work performed to develop a reference plant model for a "fuel element" type heat pipe cooled micro-reactor.

This reference plant model was developed from the INL proposed "Design A" that was detailed in [Sterbentz et al, 2018]. The following major modifications were made to the INL design:

- Increased heat pipe diameter: as the heat pipe limiting heat load due to the sonic limit scales with the square of the vapor core diameter, even small changes in this parameter can significantly reduce the total number of heat pipes required thereby decreasing the complexity of the model.

- Usage of metallic fuel: this was studied in the INL report and could provide advantages for a passively cooled system that relies on decay heat rejection from the reactor pressure vessel wall.

- Placement of control drums: as in the LANL and INL designs, rotating control drums are used for reactivity control during normal operation. In this model, they are moved from outside the core to the lattice corners to give a thinner radial reflector region.

- Decay heat removal: in the LANL design, decay heat removal is accomplished by the addition of a secondary heat exchanger to the heat pipe array. Instead, this model uses a vessel cooling system primarily to allow for testing of this type of component in SAM.

The major design elements are detailed below in the Fuel Element Design, Core Design, and Reactivity Control sections.

\subsubsection{Fuel element design}

The fuel element design selected for this work is a modified form of that denoted as "Design $A$ " in [Sterbentz et al, 2018]. In this design the monolithic core structure proposed by LANL for their Megapower design has been replaced with a collection of individual fuel elements. Each fuel element consists of a central heat pipe surrounded by a hexagonal shaped fuel slug contained within a stainless steel can as depicted in Figure 1. The large light blue region denotes the heat pipe vapor core region that occupies about $28 \%$ of the fuel element cross-sectional area. The darker blue and gray annular sections represent the heat pipe wick and wall regions respectively. The gold hex-shaped annular region is the fuel slug and occupies about $50 \%$ of the cross-sectional area. 


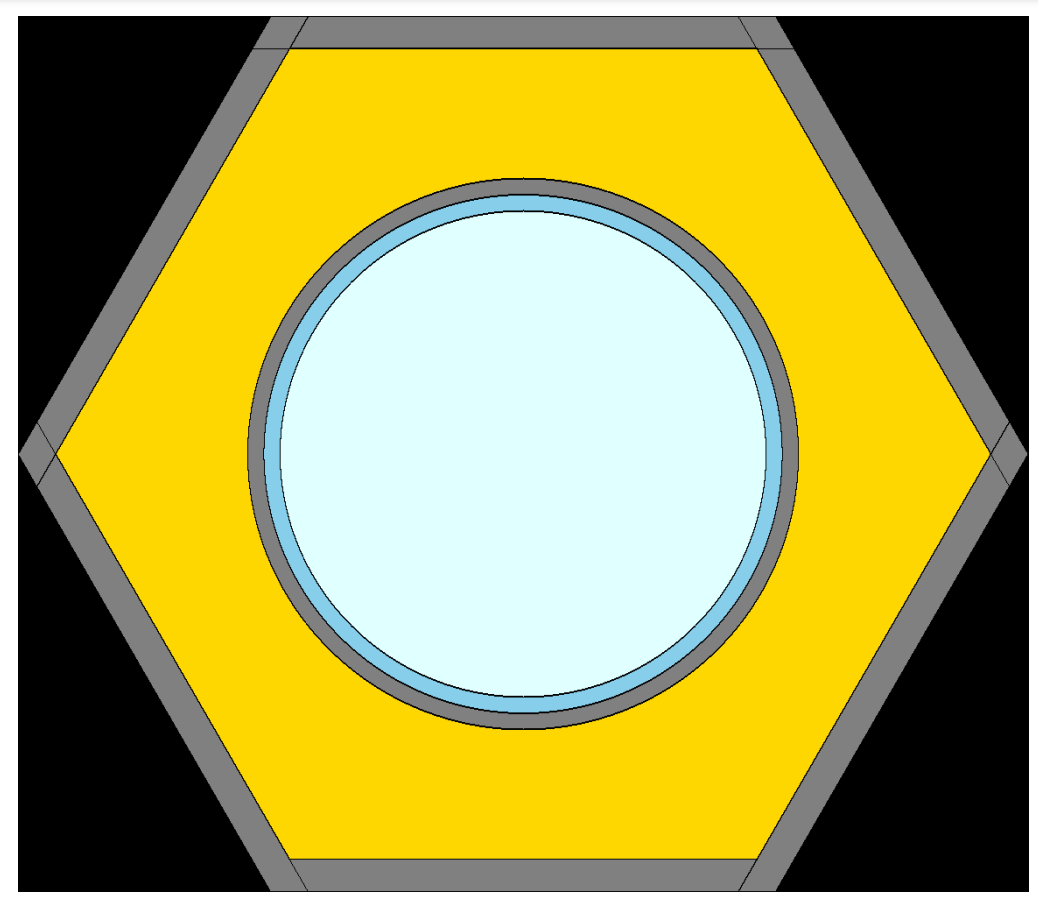

Figure 1 Fuel element horizontal cross-section.

Note that, unlike the INL design, this model does not feature an "inner clad" between the fuel slug and the heat pipe wall. This modification was made solely to simplify the resulting model. Similarly, that while the thermal resistance between the heat pipe wall and the fuel slug is modeled, the thermal resistances due to gaps between the fuel slug and the hex can, and between neighboring fuel elements are not modeled. An efficient and user-friendly way to include these resistances has been identified as a code development gap. As shown in Figure 2, axial reflectors comprised of beryllium oxide (light gray material) are placed immediately above and below the fueled region as in the INL design. The axial extent of Figure 2 is from the bottom of the core support plate (dark gray material) to the top of the upper axial reflector. Above the upper axial reflector would likely be a relatively long gas-filled space to serve as a fission gas plenum followed by an axial shield. Consequently, the neutronics model only considers the axial region depicted in Figure 2 and neutrons exiting this region are considered as lost due to leakage. 


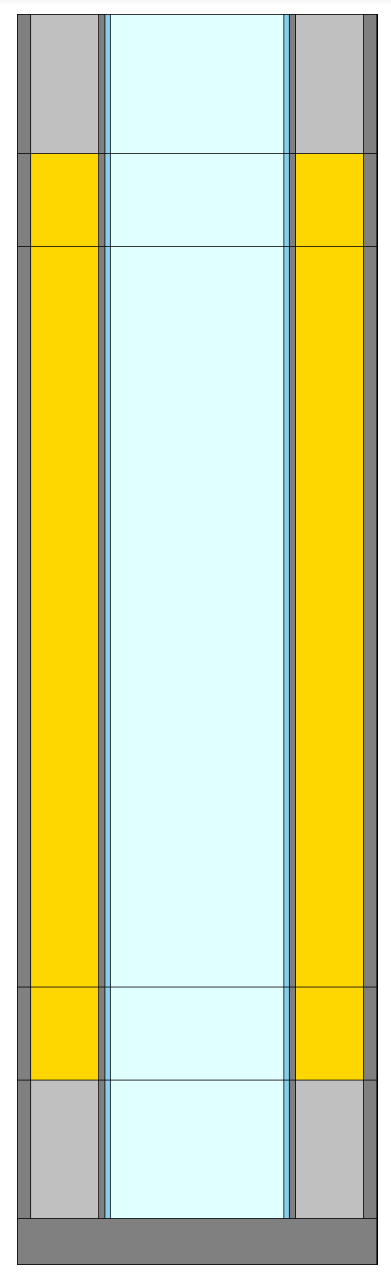

Figure 2 Axial cross-section of modeled portion of fuel element.

The materials selected for the fuel element are listed in the table below and are those of the INL Design A with one notable exception. The exception is the fuel itself. The INL design used uranium dioxide ceramic fuel but also conducted a sensitivity study using a metallic fuel consisting of uranium with a $10 \%$ weight fraction of zirconium (U-10Zr) as was tested in the fast spectrum EBR-II and FFTF test reactors. As the LANL monolith design has also proposed using $\mathrm{UO}_{2}$ ceramic fuel, metallic fuel was selected for this reference plant model. The INL sensitivity study concluded that the usage of metallic fuel would allow for lower values of fuel enrichment. In addition, metallic fuel's relatively high value of thermal conductivity compared to ceramic $\mathrm{UO}_{2}$ makes it more suitable for passive decay heat removal via conduction to the vessel wall and rejection to the environment via a vessel cooling system (VCS). Finally, as in the INL sensitivity study, the U-10Zr metallic fuel was assumed to have a porosity of $10 \%$ to allow for the swelling due to fission gas release. The composition and dimensions of fuel elements are listed in Table 1 and Table 2, respectively. 
Table 1 Composition of fuel element

\begin{tabular}{|l|c|}
\hline Region & Material \\
\hline Fuel (18.1\% enriched) & U-10Zr \\
\hline Axial Reflectors & BeO \\
\hline Heat Pipe Wick & SS-316 \\
\hline Heat Pipe Wall & SS-316 \\
\hline Heat Pipe Working Fluid & Potassium \\
\hline Hex Can Wall & SS-316 \\
\hline Core Support Plate & SS-316 \\
\hline
\end{tabular}

Table 2 Dimension of fuel element

\begin{tabular}{|l|c|}
\hline Parameter & Value \\
\hline Heat Pipe Vapor Core Diameter (cm) & 3 \\
\hline Heat Pipe Wick Thickness (mm) & 1 \\
\hline Heat Pipe Wall Thickness (mm) & 2.5 \\
\hline Fuel Slug Apothem (cm) & 2 \\
\hline Hex Can Wall Thickness (mm) & 5 \\
\hline Support Plate Thickness (cm) & 15 \\
\hline Axial Reflector Thickness (cm) & 100 \\
\hline Fuel Slug Length (cm) & 100 \\
\hline
\end{tabular}

\subsubsection{Core design}

To reduce the complexity of this reference plant model, the diameter of the heat pipe vapor core was increased to allow for a greater heat load and hence a reduced number of heat pipes for a given reactor power level. Specifically, the heat pipe vapor core was sized using the sonic limit to allow for a nominal heat load of $26 \mathrm{~kW}$ with a margin of about $20 \%$. The resulting vapor core diameter was $3 \mathrm{~cm}$, almost double that of the LANL and INL designs, but comparable to those tested by [Dickinson, 1996]. Increasing the vapor core diameter allowed for the total number of heat pipes, and hence fuel elements, to be reduced from 1,134 in the INL design to a more manageable value of 192 for this reference plant having a thermal power of $5 \mathrm{MW}$. 
As in the INL Design A, a single safety shutdown control rod is located at the center of the core as depicted in Figure 3 (the green cylinder). However, again for the sake of reduced model complexity, the size of the safety control rod was constrained to fit within a single fuel element hex can rather than the large central rod of the INL design that had a diameter equal to about 6 fuel elements. Also, as noted above, the rotating control drums were moved to the corners of the hexshaped core region thereby displacing some fuel elements. The radial reflector is composed of aluminum oxide $\left(\mathrm{Al}_{2} \mathrm{O}_{3}\right)$ ceramic as in the LANL and INL designs. The important core design parameters are listed in Table 3.

Table 3 Core design parameters

\begin{tabular}{|l|c|}
\hline Core Design Parameter & Value \\
\hline Thermal Power (MWt) & 5 \\
\hline Fuel Enrichment (wt\%) & 18.1 \\
\hline BOL Core K-effective & 1.02321 \\
\hline Number of Heat Pipes & 192 \\
\hline Average Heat Pipe Power (kW) & 100 \\
\hline Core Height (cm) & 34.6 \\
\hline Effective Side Reflector Thickness 1 (cm) & $\mathrm{Al}_{2} \mathrm{O}_{3}$ \\
\hline Side Reflector Material & 113.4 \\
\hline RPV Inner Diameter (cm) & 2.5 \\
\hline RPV Wall Thickness (cm) & $\mathrm{SS}^{3} 316$ \\
\hline RPV Wall Material & \\
\hline
\end{tabular}

${ }^{1}$ Defined as the thickness necessary to give the cross-sectional area of the side reflector with an outside diameter equal to that of the RPV inside diameter. 


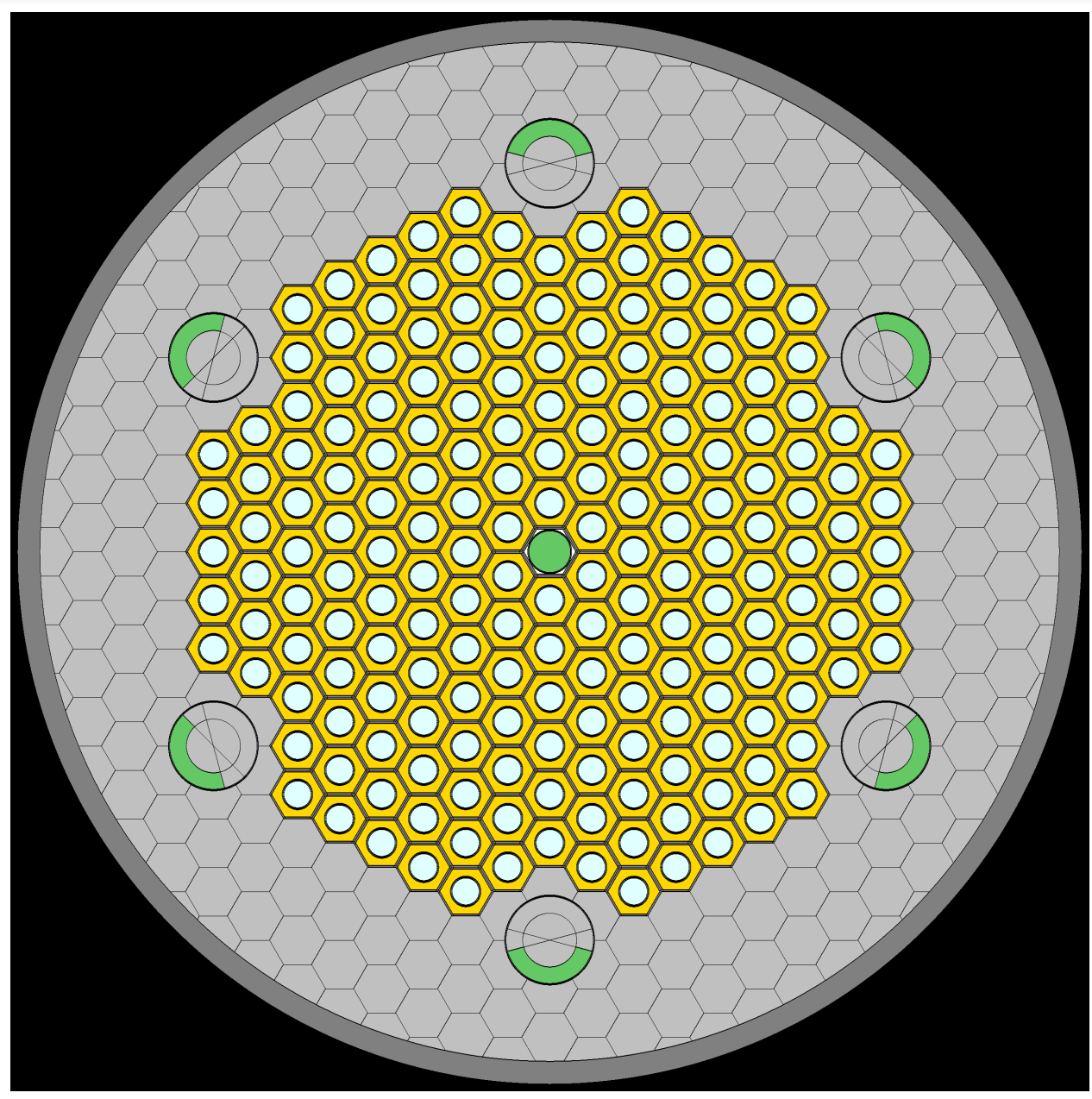

Figure 3 Cross-section of fuel element micro-reactor core.

Figure 4, a Serpent mesh plot, graphically illustrates both the radial power distribution using a "hot" color map and the thermal flux distribution with a "cold" color map. The black circular arcs depict the dearth of thermal neutrons in the $\mathrm{B}_{4} \mathrm{C}$ absorber region of the control drums at their critical position of $67^{\circ}$. The radial power peaking factor is 1.316 with the highest power fuel elements being those surrounding the central control rod location. Due to the control drum rotation, the core only has a $60^{\circ}$ symmetry and the lowest power fuel elements are those adjacent to the $\mathrm{B}_{4} \mathrm{C}$ arc on the core periphery as shown in Figure 5. 


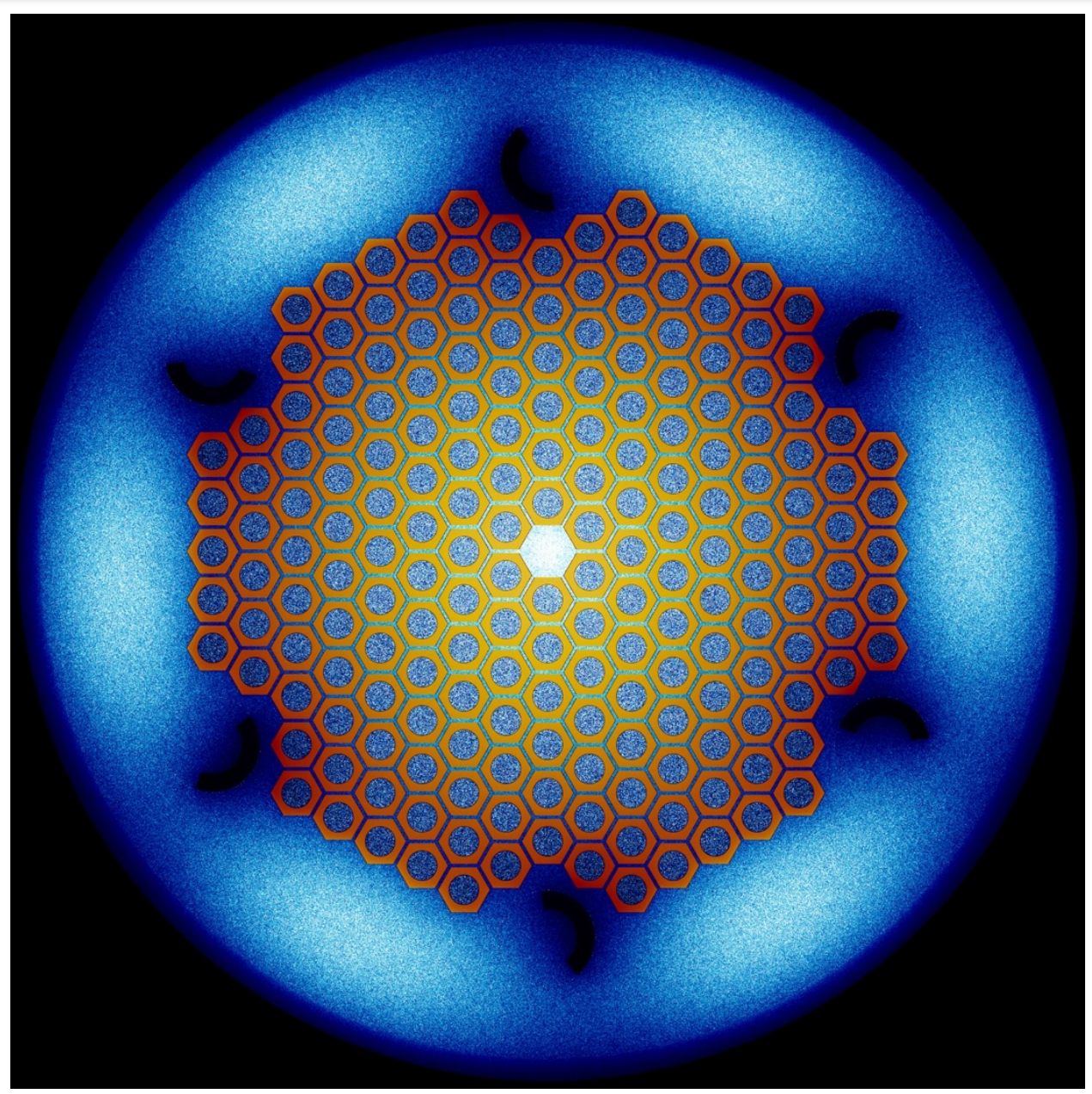

Figure 4 Serpent mesh plot denoting radial power distribution (hot color map) and thermal flux distribution (cold color map). 


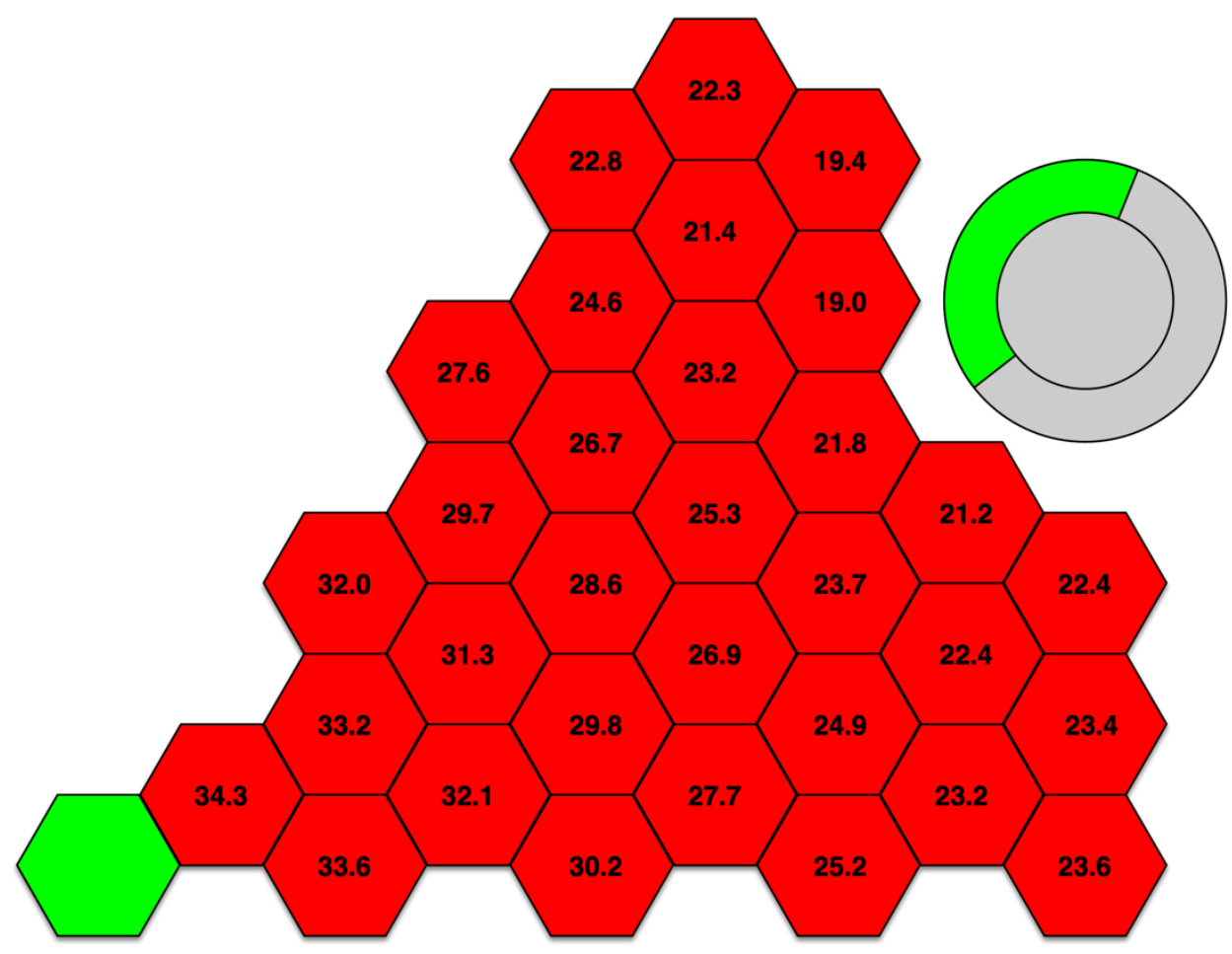

Figure 5 Fuel element radial power distribution $(\mathrm{kW})$.

Figure 6 is an axial depiction of the Serpent mesh plot for the same full power BOL conditions also showing the fission power (hot color map) and thermal neutron flux (cold color map). The neutron streaming from the heat pipes at the top of the core is readily apparent. Also apparent is the thermalization and reflection at the bottom of the core due to the $\mathrm{BeO}$ reflector and the stainless-steel support plate. This effect is dramatically evident in the axial power profile given in Figure 7.

At beginning-of-life (BOL) conditions the axial peaking factor is 1.198 and has noticeable peaks at the boundary between the fuel and the $\mathrm{BeO}$ axial reflectors with the largest peak at the bottom of the core. These peaks are due to the softening of the spectrum by scattering in the $\mathrm{BeO}$ axial reflectors and subsequent reflection back into the core. The neutronics model for this core design is symmetric in the axial direction with the exception of the stainless-steel core support plate and it is reflection from this plate that gives rise to the large bottom peak. 


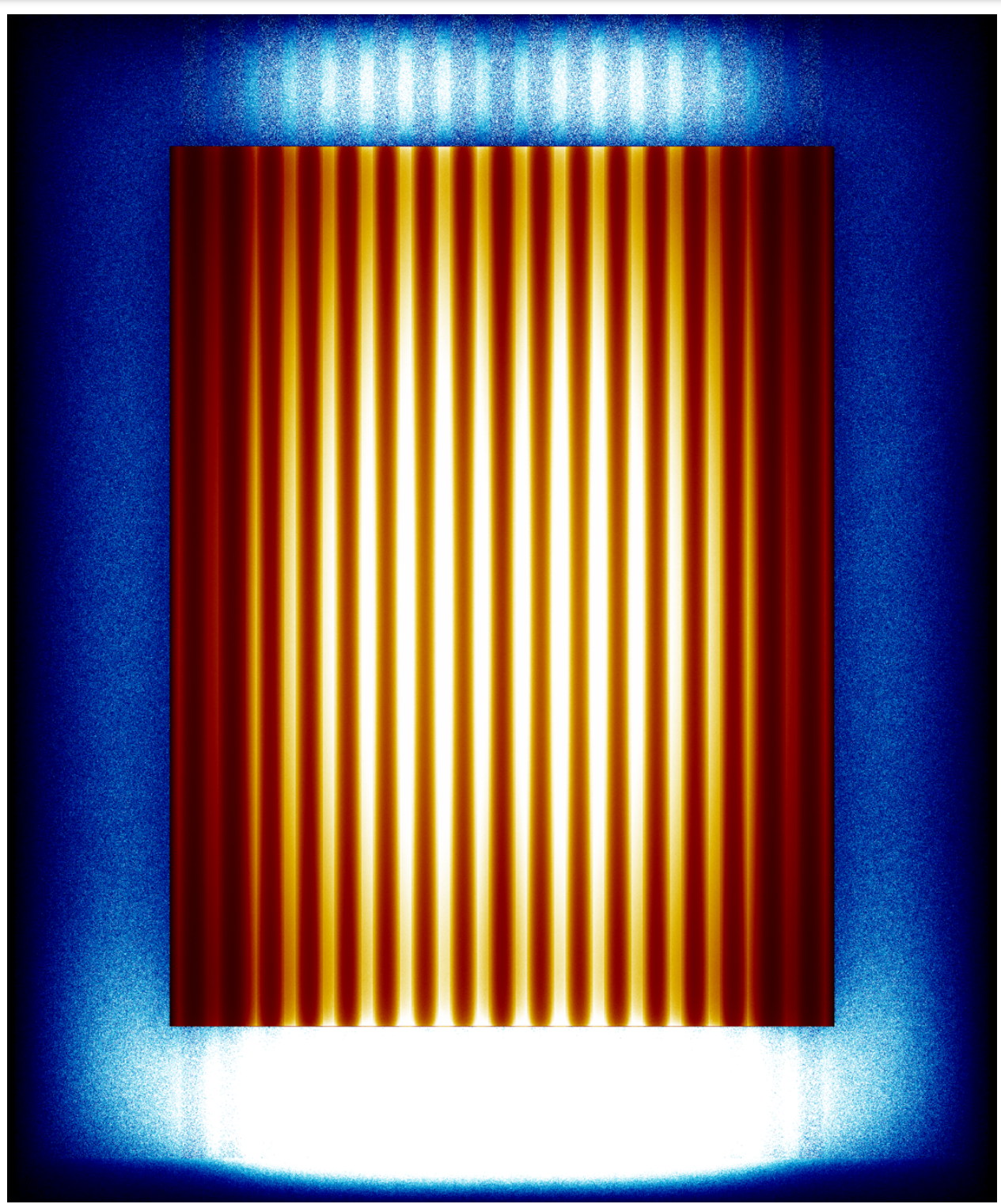

Figure 6 Axial cutaway of Serpent mesh plot depicting fission power (hot color map) and thermal neutron flux (cold color map). 


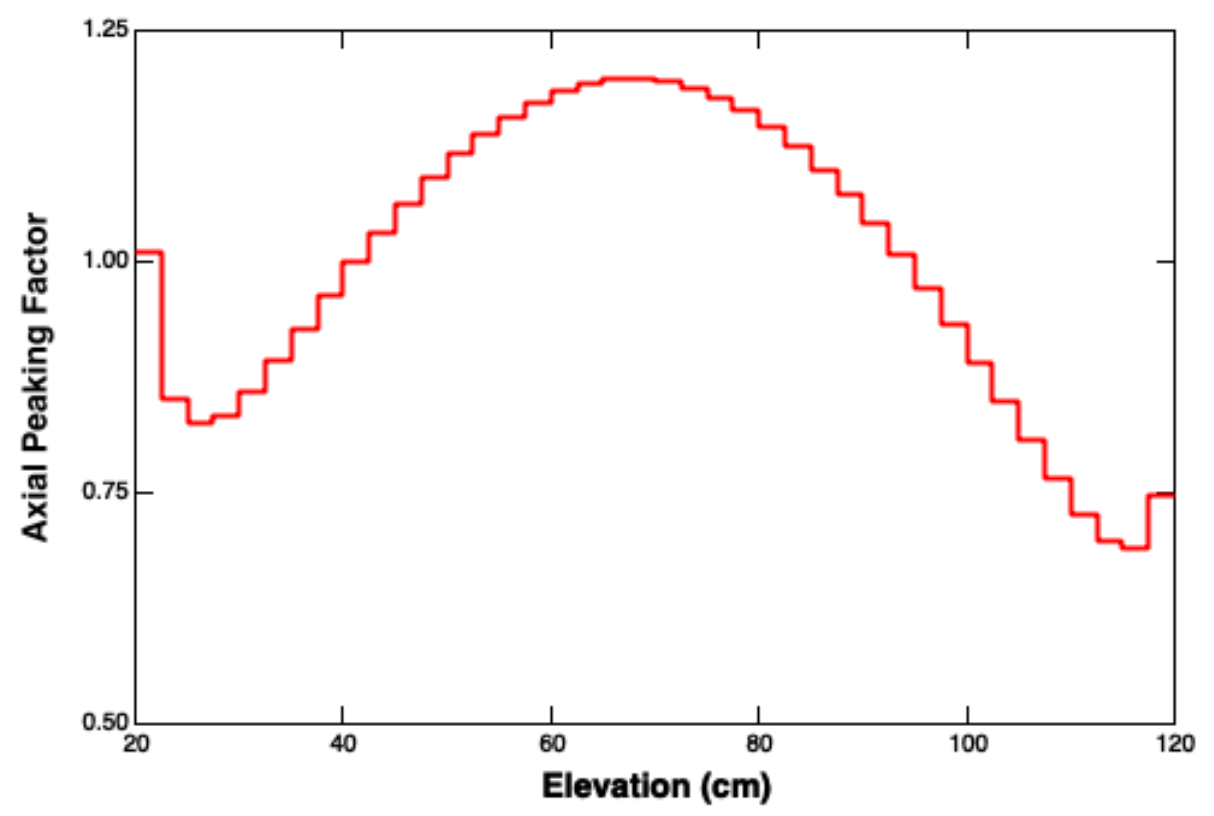

Figure 7 Axial power profile at BOL.

\subsubsection{Reactivity control}

To provide margin for core burnup, an excess initial reactivity similar to that of the INL design was allowed for. The beginning-of-life k-effective as calculated by Serpent with the core in its most reactive state was 1.02321 yielding an excess reactivity of $2321(\mathrm{pcm})$.

As discussed above a single shutdown control rod is provided at the center of the core. This rod would be fully withdrawn during normal operation and during unprotected transients. The constraint of placing the rod within one fuel element hex reduces its pellet diameter to $4.65 \mathrm{~cm}$ and its worth to 3167 (pcm). So, at beginning-of-life with the control drums fully rotated away from the core, the insertion of the shutdown rod would only yield a shutdown margin of 846 (pcm). Relevant dimensions and materials are provided in Table 4.

Table 4 Dimensions and material properties of control rod

\begin{tabular}{|l|c|}
\hline Shutdown Control Rod Parameter & Value \\
\hline Absorber Material & $\mathrm{B}_{4} \mathrm{C}$ \\
\hline Absorber Material B-10 Enrichment (wt $\%)$ & 90 \\
\hline Absorber Pellet Diameter $(\mathrm{cm})$ & 4.65 \\
\hline SS Clad Thickness $(\mathrm{mm})$ & 1 \\
\hline Clad Outer Diameter $(\mathrm{cm})$ & 4.9 \\
\hline
\end{tabular}


For control of reactivity during normal operation, six cylindrical control drums are provided at the corners of the hex-shaped core. The absorber material is $\mathrm{B}_{4} \mathrm{C}$ placed in $150^{\circ}$ annular sectors at the edge of the control drums. The most reactive state of the core is with the control drums fully rotated $\left(180^{\circ}\right)$ away from the core as depicted in Figure 3 thereby minimizing absorption while maximizing reflection. Rotation of the drums towards the core causes a decrease in reactivity of $3368(\mathrm{pcm})$ and would provide a redundant means of core shutdown. The critical position, $\mathrm{k}_{\mathrm{eff}}=$ 1 , is realized with the shutdown rod fully withdrawn and the control drums rotated $67^{\circ}$ and this is the condition assumed at the starting point for the transient analysis described in this report. Relevant dimensions and materials for the control drums are provided in Table 5. A summary of the reference plant design reactivity control parameters is given in Table 6 .

Table 5 Dimensions and material properties of control drum

\begin{tabular}{|l|c|}
\hline Control Drum Parameter & Value \\
\hline Absorber Material & $\mathrm{B}_{4} \mathrm{C}$ \\
\hline Absorber Material B-10 Enrichment (wt $\%)$ & 90 \\
\hline Absorber Inner Diameter (cm) & 6.5 \\
\hline Control Drum Reflector Material & $\mathrm{Al}_{2} \mathrm{O}_{3}$ \\
\hline Absorber Thickness (cm) & 2 \\
\hline Absorber Sector Angle & $150^{\circ}$ \\
\hline SS Clad Thickness (mm) & 1 \\
\hline Clad Outer Diameter (cm) & 5.35 \\
\hline Control Drum Well Inner Diameter (cm) & 5.4 \\
\hline
\end{tabular}

Table 6 Reference plane design reactivity control parameters

\begin{tabular}{|l|c|}
\hline Reactivity Control Parameter & Value \\
\hline BOL Core K-effective & 1.02321 \\
\hline Shutdown Control Rod Worth (pcm) & 3167 \\
\hline Number of Control Drums & 6 \\
\hline Total Control Drum Worth (pcm) & 3368 \\
\hline Control Drum Critical Position & $67^{\circ}$ \\
\hline
\end{tabular}




\subsection{Heat pipe modeling in SAM}

The heat pipe is a very effective device for transmitting heat at high rates through a small crosssectional area over a long distance but with small temperature drops. The advantages of using a heat pipe over other conventional methods include for example exceptional flexibility, simple construction, easy maintenance, and easy control with no external pumping power.

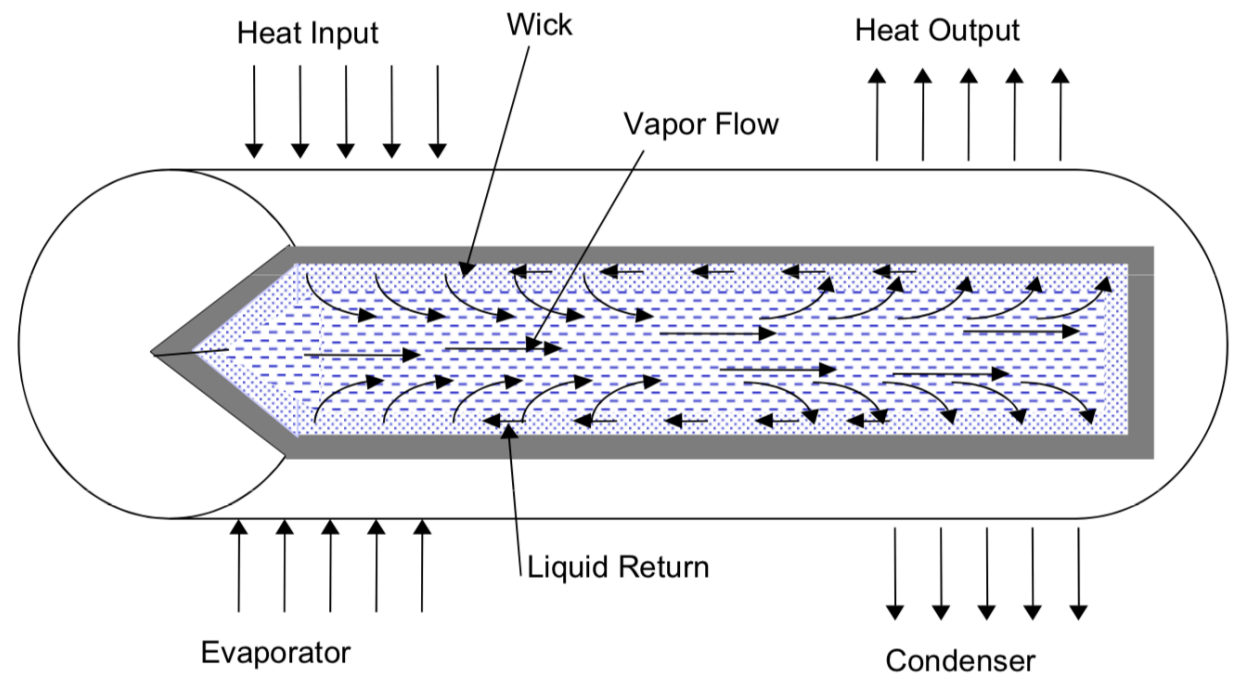

Figure 8 A conventional heat pipe showing the principle of operation and circulation of the working fluid

Figure 8 [Faghri, 1995] shows a schematic of the conventional heat pipe that shows the principle of operation and circulation of the working fluid. The components of a heat pipe are a sealed container which includes the pipe wall and end caps, a wick structure, and a small amount of the working fluid. The conventional heat pipe contains mainly three parts: evaporator section, adiabatic section, and the condenser section. The external heat is applied to the evaporator section through the pipe wall and wick structure. The external heat vaporizes the working fluid in the wick structure, which increase the vapor pressure in the evaporator region. The vapor pressure then drives the vapor through the adiabatic section to the condenser section. In the condenser section, the vapor condenses and releases its latent heat to the external heat sink through the wick structure and pipe wall. The capillary pressure created by the menisci in the wick drives the condensed fluid back to the evaporator section. This process will continue as long as the capillary pressure is enough to drive the condensed working fluid back to the condenser region. As discussed, the heat pipe makes use of the phase change of the working fluid and transport a large amount of heat from the evaporator to the condensation end with very small temperature drops. This feature makes the heat pipe an ideal means to extract thermal power from a nuclear reactor. In contrast to the traditional nuclear reactor system that makes use of pumped loop for extracting the thermal power, the heat pipes reactors make use of hundreds of heat pipes for removing the thermal power (including the decay heat) passively [McClure et al. 2015]. The reliability and safety of the reactor system can be significantly improved.

The thermal fluid phenomena in a heat pipe can be divided into four basic categories: 1) heat conduction in the heat pipe wall; 2) liquid flow and heat transfer in the wick structure; 3 ) interfacial mass, momentum, and energy transfer in the liquid vapor interface; and 4) vapor flow in the heat pipe core. The heat conduction and the vapor flow are usually modeled as a conjugate heat transfer 
problem. The main difficulties in modeling the heat pipe are the conjugate interface mass/momentum/energy transfer between the wick and the vapor core, and the vapor flow in the vapor core region. The main approximation for modeling the heat pipe in SAM is that the vapor core can be modeled as a superconductor with a very large thermal conductivity. The heat from the source will be transported to the vapor core from the interface between the wick and the vapor core in the evaporator region, then be conducted axially through the vapor core to the condenser region, and then be transported to wick from the interface between the vapor core and the wick in the condenser region, and finally be transported to the heat sink.

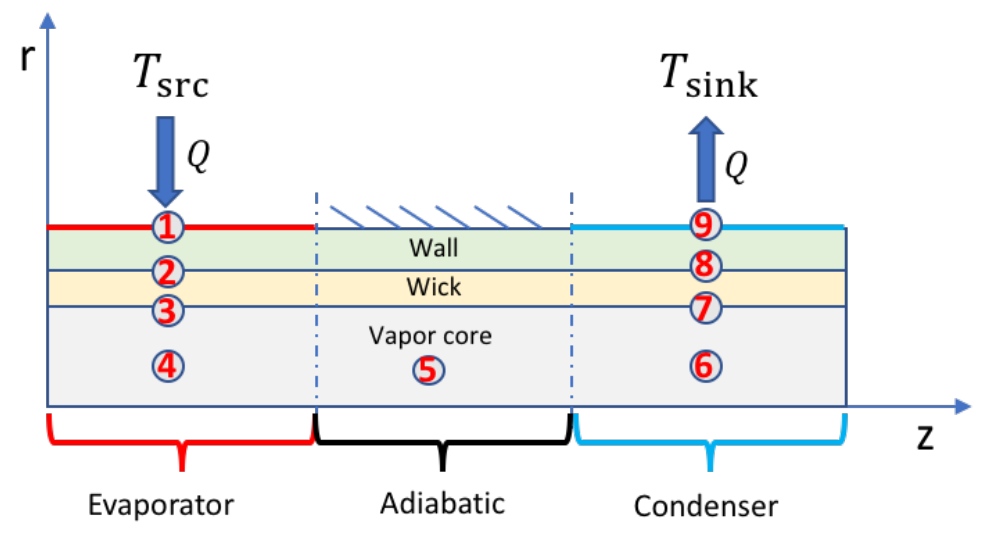

Figure 9 A conventional heat pipe in axsymmetric coordinate

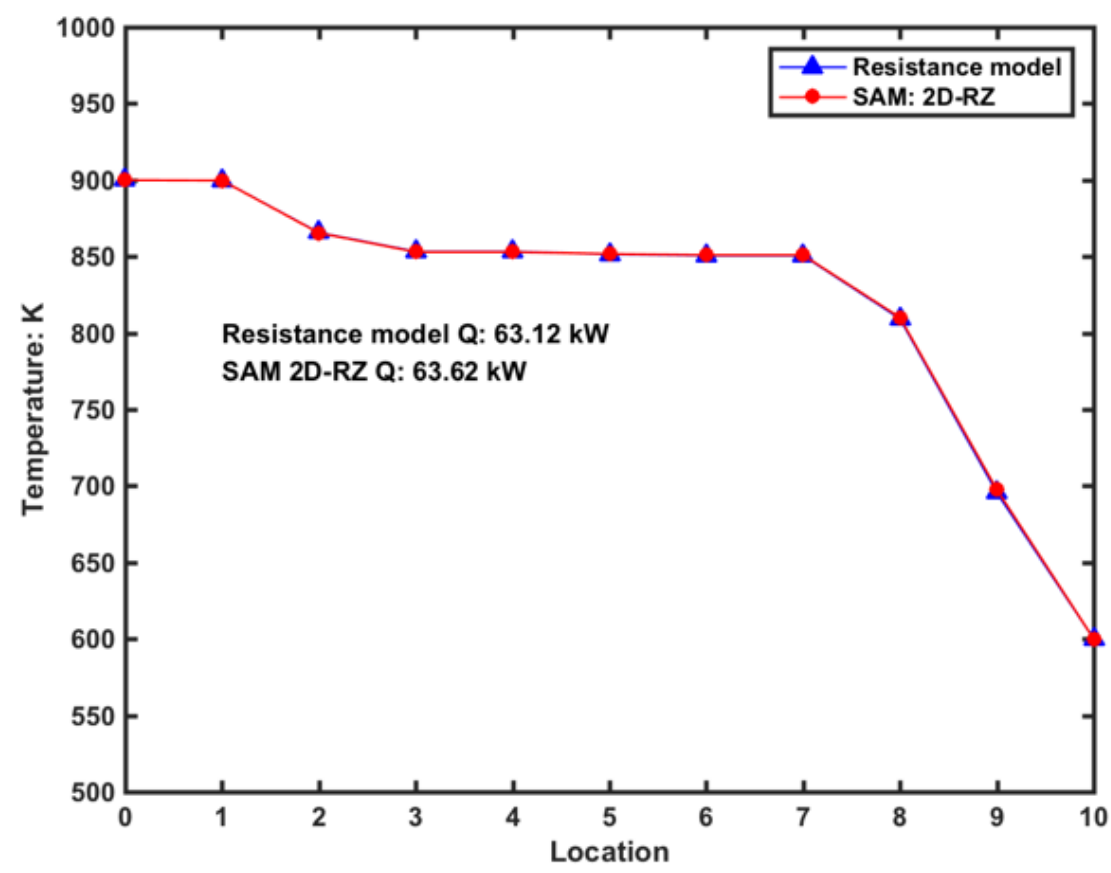

Figure 10 Heat pipe steady-state verification results

The heat pipe is modeled in SAM as an axisymmetric $2 \mathrm{D}-\mathrm{RZ}$ heat structure. In the 2D-RZ heat conduction approach, the heat pipe wall, heat pipe wick, and heat pipe vapor core are modeled 
as axisymmetric 2D-RZ blocks, with all heat being transported through heat conduction. The wall region is modeled as the normal container material, the is modeled as a solid material using an effective thermal conductivity, and the vapor core is modeled as a superconducting material with an ad-hoc very large thermal conductivity. Figure 9 shows the schematic of the conventional heat pipe modeled in SAM. The modeling methodology in SAM was verified with the thermal resistance model [Hu et al. 2019b]. Figure 10 shows the comparison of average temperature at different locations from SAM prediction and the resistance model, and the comparison of the heat transport capacity (i.e. $Q$ in the figure) from SAM prediction and the resistance model. 


\section{Multi-Physics Coupling Methodology}

The analysis of the heat pipe micro reactors requires capturing the phenomena of several fields of physics, e.g. reactor kinetics, system thermal hydraulics, thermomechanics, etc. The nonlinearities brought by the different physics needs to be resolved through a coupling approach. It would be ideal to solve the different physics simultaneously; however, it is quite challenging or unfeasible. A common approach to resolve the nonlinearities is to apply the so-called tight coupling approach. The tight coupling consists of solving each physics problem separately and ensures the global convergence through Picard iterations. The main challenge in the tight coupling lies in the transfer between different physics problems. The MOOSE's MultiApp system [Gaston et al. 2009; Gaston et al. 2015] provides an efficient framework for this purpose.

\subsection{Multi-physics coupling models}

The numerical model consists of the following sub-models coupled to each other through the MOOSE MultiApp system. A schematic representation of interrelation is given on Figure 11.

- RK: one whole-core, 3-D MAMMOTH input with homogenized blocks to solve the linearized Boltzmann transport equation. The multigroup cross-sections are computed with a heterogeneous Serpent model. A Super Homogenization (SPH) correction is applied to run transport-corrected diffusion. The main purpose of this input is to compute the power density distribution and transfer it to the other physics.

- HC: one whole-core, 3-D SAM input for the heat conduction calculation in the reactor core. It models the heat conduction in the core and convection at its boundaries. It takes the power density from the RK model and calculate the solid temperature in different regions (e.g. fuel, reflector, reactor vessel, plate, etc.).

- HPs: 192 instantiations of a SAM input for modeling the individual heat pipe. Each individual heat pipe is coupled to a cooling pipe to model the secondary heat exchangers. The individual heat pipe takes the thermal heat from the fuel cell by conduction across the heat pipe evaporator wall. The condenser wall of the heat pipe is coupled with a cooling pipe through conjugate heat transfer.

- RCCS: a SAM input for modeling the reactor cavity cooling system. It takes the radiation heat from the reactor vessel and transport it to a coupled cooling pipe. Under the circumstance that the heat removal through the heat pipes is not available, the RCCS plays the key role in taking the heat out of the reactor core.

- TM-Fuel: 192 instantiations of a Tensor Mechanics input for modeling the axial expansion of the fuel elements. It takes the fuel temperature from the $\mathrm{HC}$ and return the axial expansion for reactivity feedback calculation in RK. There is one sub-model for each individual fuel cell.

- TM-Plate: a Tensor Mechanics input for modeling the radial expansion of the reactor core. It takes the solid temperature in the support plate from the $\mathrm{HC}$ and returns the radial expansion for reactivity feedback calculation in RK. 
- Joint: a dummy input model to initiate the simulation flow of the HC and TM. This model is added to the coupling chain because of the difference in the meshes used by the RK and HC model. It also avoids the direct communications between TM sub-Apps and the HC sub-App so that the TM sub-Apps will not participate the Picard iterations needed for HC, HPs, and RCCS sub-Apps.

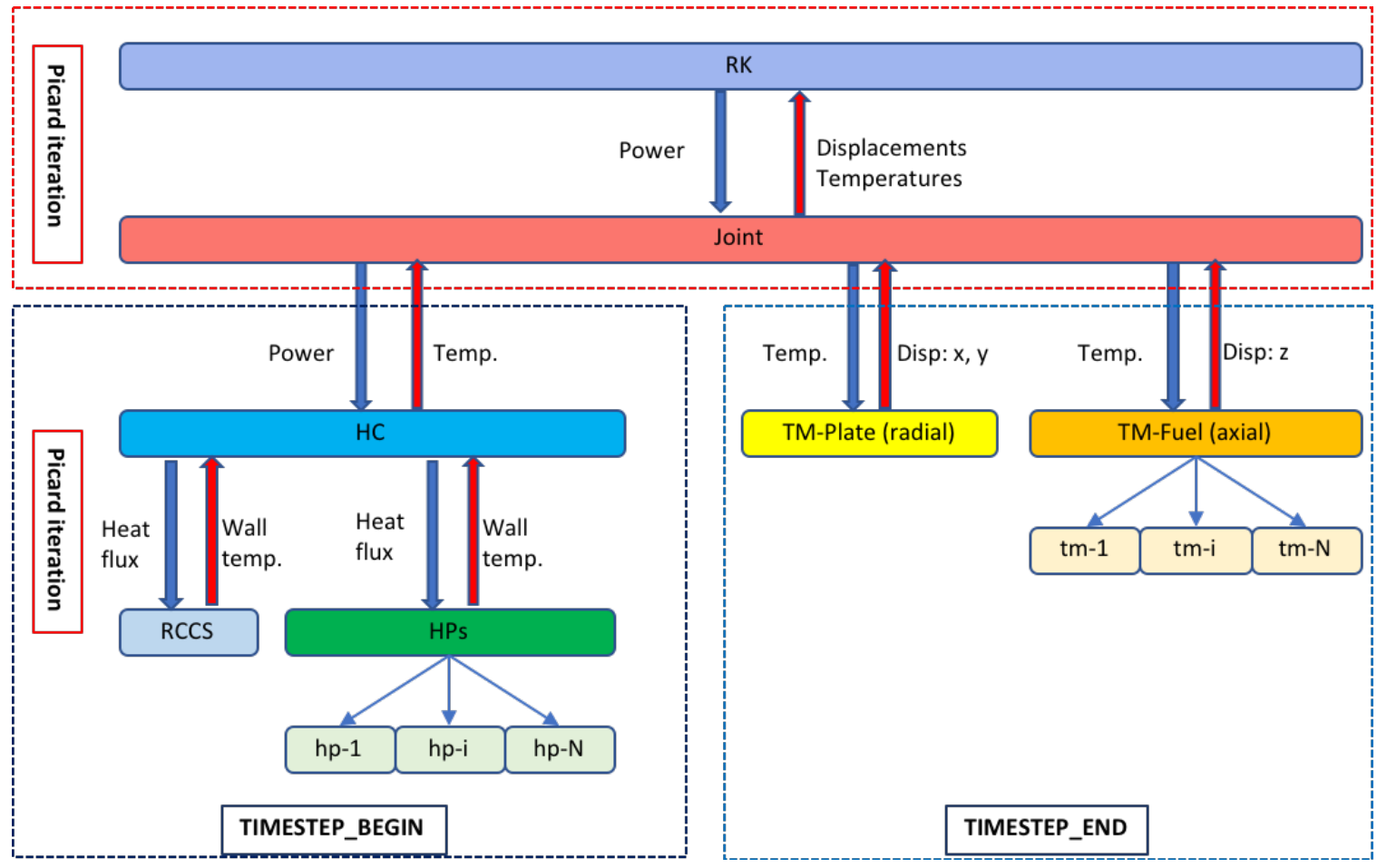

Figure 11 Schematic of the multi-physics coupling method for heat pipe micro reactors

\subsection{Modeling of reactor kinetics with MAMMOTH}

MAMMOTH is based on MOOSE [Gaston et al, 2015], a finite element method framework that focuses on multi-physics simulations with fully or tightly coupled physics applications. In addition to implementing reactor physics specific capabilities such as depletion and equivalence methods, MAMMOTH seamlessly interfaces with several other MOOSE applications including Rattlesnake [Wang, 2015] for radiation transport algorithms, MOOSE modules for heat transfer and solid mechanics, BISON [Williamson et al., 2012] for fuel performance modeling and Pronghorn [Novak et al., 2018] \& [Zou et al., 2018] \& SAM [Hu, 2017] for thermal fluids calculations. Rattlesnake is a neutron transport solver that is incorporated within MAMMOTH as a submodule and, in this work, the usage of the name MAMMOTH will be meant to infer MAMMOTH/Rattlesnake working as a single neutronics application.

The Rattlesnake neutron transport solver incorporates a variety of spatial and angular discretization methods including diffusion, $P N$ and $S N$ (both $1 s t$ and 2 nd order formulations). In this work, we exclusively use the continuous FEM diffusion solver. In addition, the diffusion calculation is "corrected" using the super-homogenization ( $\mathrm{SPH}$ ) equivalence scheme. SPH is an 
advanced implementation of the traditional equivalence procedure [Hebert and Mathonniere, 1993] developed at INL [Ortensi et al, 2018] \& [Laboure et al, 2018] and is employed to ensure preservation of the reaction rates between the reference Monte Carlo model and the cross section set used in the MAMMOTH model.

$\mathrm{SPH}$ factors, $\mu_{m, g}$, are used to correct the cross sections in region $m$ and energy group $g$. Using flux-volume normalization, they are defined by:

$$
\mu_{m, g}=\frac{\phi_{m, g}^{r e f}}{\phi_{m, g}} \frac{\bar{\phi}_{g}}{\bar{\phi}_{g}^{r e f}}
$$

where

$$
\begin{gathered}
\bar{\phi}_{g} \equiv \frac{\sum_{m=1}^{M} V_{m} \phi_{m, g}}{\sum_{m=1}^{M} V_{m}} \\
\bar{\phi}_{g}^{r e f} \equiv \frac{\sum_{m=1}^{M} V_{m} \phi_{m, g}^{r e f}}{\sum_{m=1}^{M} V_{m}}
\end{gathered}
$$

and $M$ is the number of macro regions.

The SPH corrected neutron diffusion equation is written as:

$$
\begin{aligned}
-\nabla \cdot \mu_{m, g} D_{m, g} & \nabla \phi_{g}(\vec{r})+\mu_{m, g} \Sigma_{m, g} \phi_{g} \\
& =\frac{\chi_{g}}{k_{e f f}} \sum_{g^{\prime}=1}^{G} \mu_{m, g^{\prime}} v \Sigma_{f_{m, g^{\prime}}} \phi_{g^{\prime}}+\sum_{g^{\prime}=1}^{G} \mu_{m, g^{\prime}} v \Sigma_{s 0_{m}}^{g \leftarrow g^{\prime}} \phi_{g^{\prime}}
\end{aligned}
$$

where

$$
\phi_{m, g}=\int_{V_{m}} \phi_{g} d \vec{r}
$$

To evaluate the SPH factors, in addition to the normal mesh and cross-section information, MAMMOTH needs to be provided with both values for the reference fluxes, $\phi_{m, g}^{r e f}$, and the corresponding reference eigenvalue, $k_{e f f}$. The resulting set of nonlinear equations is solved simultaneously for all equivalence regions and energy groups using the Preconditioned JacobianFree Newton Krylov (PJFNK) solver available in MOOSE. MAMMOTH's SPH equivalence scheme can provide the accuracy of a transport solution without the associated computational burden. This project will test the accuracy of the SPH equivalence scheme for a small fast reactor that is leakage dominated and utilizes the displaced mesh capability to handle reactivity effects due to geometry changes caused by thermal expansion.

\subsubsection{Cross-section and SPH factor generation}

The neutron transport equation solved by MAMMOTH for both steady-state and transient reactor analyses requires the specification of macroscopic cross-sections for the various regions of the reactor core. In addition, to use the $\mathrm{SPH}$ equivalence method, a $3 \mathrm{D}$ reference solution is 
required for each state point where cross-sections are evaluated. To accomplish this, the workflow depicted in Figure 12 is followed and the Serpent [Leppanen, 2007] Monte-Carlo code is used in conjunction with MAMMOTH.

The first step is the generation of the base Serpent model that fully describes both the detailed geometry and the isotopic composition of the materials. In this work, the nominal geometric dimensions are those given above in the Micro-Reactor Design section and are assumed to correspond to the reactor normal operating condition with a temperature of $900 \mathrm{~K}$. A direct result of this assumption is a mismatch in the critical control drum angle. Effect of this uniform temperature assumption will be studies later in Section 4. A mid-core cross-section of the Serpent model was given in Figure 3 above. The isotopic composition for all of the materials was taken from Appendix A of the INL report [Sterbentz et al, 2018].

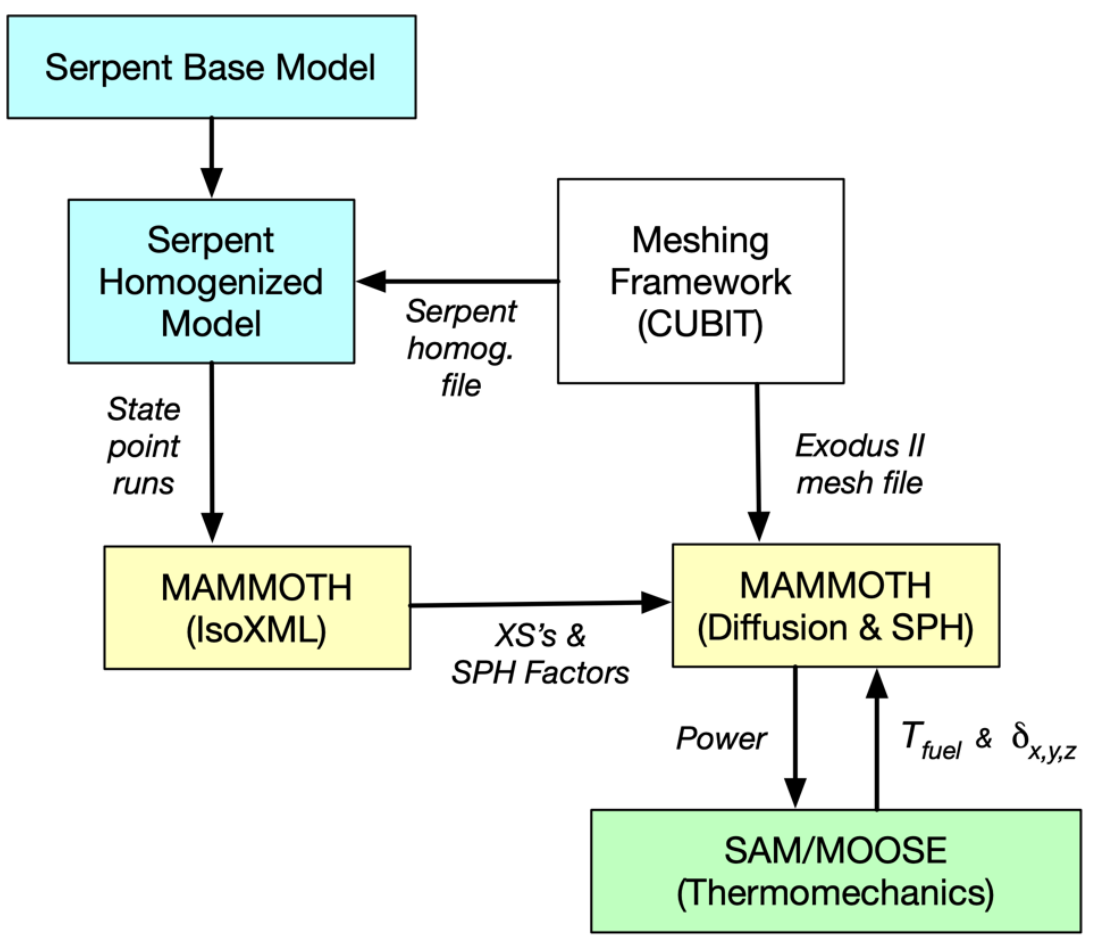

Figure 12 Analysis workflow for cross-section and SPH factor generation.

The next step entails the preparation of the Constructive Solid Geometry (CSG) input for the homogenized domain used in the 3D MAMMOTH simulation. A Python meshing framework that accesses the CUBIT API was developed by INL and processes the input CSG directives and generates both an Exodus II mesh file and a Serpent homogenization file. This latter file is included in the preparation of the final Serpent model that is used to generate homogenized cross sections and group-wise fluxes for SPH calculations. This automated procedure ensures geometric correspondence between the Serpent universes (regions where cross-sections are calculated) and flux detectors, and the material and equivalence ID's in in the MAMMOTH mesh file.

A set of state-point calculations with the resulting Serpent model generate the cross sections and tally output files for the full domain. Each state-point corresponds to a different combination of values of the state variables that parameterize the nuclear cross sections. The MAMMOTH cross 
section post-processor, ISOXML, compiles the tabulations and generates the YAKXS formatted file. The exodus mesh and the YAKXS file are used in the preparation of the MAMMOTH input. In the final preparatory step, MAMMOTH is used to solve the nonlinear system of equations for the SPH factors. As shown in the workflow figure, MAMMOTH and its coupled codes can then be used for either steady-state (eigenvalue) or transient multi-physics simulations.

For this demonstration calculation for a micro-reactor reference plant model, a 5-group energy structure was used for the cross-sections. The initial plan was to use the 6-group energy structure as recommended in [Cai, 2014], a condensed version of the "standard" ECCO 33-group structure often used for fast reactors. For comparison, the 6-group and 5-group energy structures are given below in Table 7.

Table 7 Comparison of 6-group and 5-group energy structures

\begin{tabular}{|c|c|c|c|}
\hline \multirow{2}{*}{ Group No. } & \multicolumn{2}{|c|}{ Group Boundary (MeV) } & $\begin{array}{c}\text { Normalized } \\
\text { Flux } \\
(\%)\end{array}$ \\
\cline { 2 - 3 } & 6-Group & 5-Group & 5.5 \\
\hline 0 & 19.6 & 20 & 28.7 \\
\hline 1 & 2.23 & 2.2313 & 58.3 \\
\hline 2 & 0.498 & 0.49787 & 6.4 \\
\hline 3 & $4.09 \mathrm{E}-02$ & $4.0868 \mathrm{E}-02$ & 1.1 \\
\hline 4 & $9.12 \mathrm{E}-03$ & $9.1188 \mathrm{E}-03$ & -- \\
\hline 5 & $4.54 \mathrm{E}-04$ & -- & -- \\
\hline- & $1.0 \mathrm{E}-11$ & $1.0 \mathrm{E}-07$ & -07 \\
\hline
\end{tabular}

Table 8 Decay constants and effective delayed neutron fractions

\begin{tabular}{|c|c|c|}
\hline $\begin{array}{c}\text { Delayed Neutron Precursor } \\
\text { Family, } \boldsymbol{i}\end{array}$ & $\begin{array}{c}\text { Decay constant, } \\
\boldsymbol{\lambda}_{\mathbf{i}}\left[\mathbf{s}^{-1}\right]\end{array}$ & $\begin{array}{c}\text { Effective delayed neutron } \\
\text { fraction, } \\
\left.\boldsymbol{\beta}_{\text {eff, }} \text { [pcm }\right]\end{array}$ \\
\hline 1 & $1.33786 \mathrm{E}-02$ & 21.4 \\
\hline 2 & $3.24447 \mathrm{E}-02$ & 119.1 \\
\hline 3 & $1.21408 \mathrm{E}-01$ & 119.0 \\
\hline 4 & $3.09045 \mathrm{E}-01$ & 288.5 \\
\hline 5 & $8.72463 \mathrm{E}-01$ & 140.1 \\
\hline 6 & 2.93112 & 58.0 \\
\hline
\end{tabular}


The difference between the two group structures is that the 5-group further condensed the "most thermal" group so that the energy level boundary at 4.54E-04 (MeV) is omitted. The last column in the above table gives the normalized values for the flux spectrum in the 5-group energy structure for the central core region of the reference plant model. Due to the small flux level below 9.12E-03 (MeV) it was necessary to condense the bottom two groups so that meaningful statistics and SPH factors could be generated. Future efforts will study the effect of the energy group structure on fast reactor kinetics.

A set of six delayed neutron precursor groups is used in transient analyses with a total $\boldsymbol{\beta}_{\text {eff }}$ of 7.46E-03. The decay constants and effective delayed neutron fractions for each family are given below in Table 8 .

\subsubsection{MAMMOTH 3D mesh}

As described in the above, the python-based meshing framework is used to generate the homogenized MAMMOTH finite element mesh show in Figure 13. The hexagonal fuel elements, the lighter blue regions, are each represented by six prisms. In the figure, there are three shades of blue used for the fuel elements corresponding to the material ID's for three different groups used for cross-section generation: 1) central group, 2) fuel elements facing control drums, and 3) fuel elements adjacent to the side reflector. The burnt sienna color depicts the side reflector, brick red the six control drums and dark blue the reactor vessel wall.

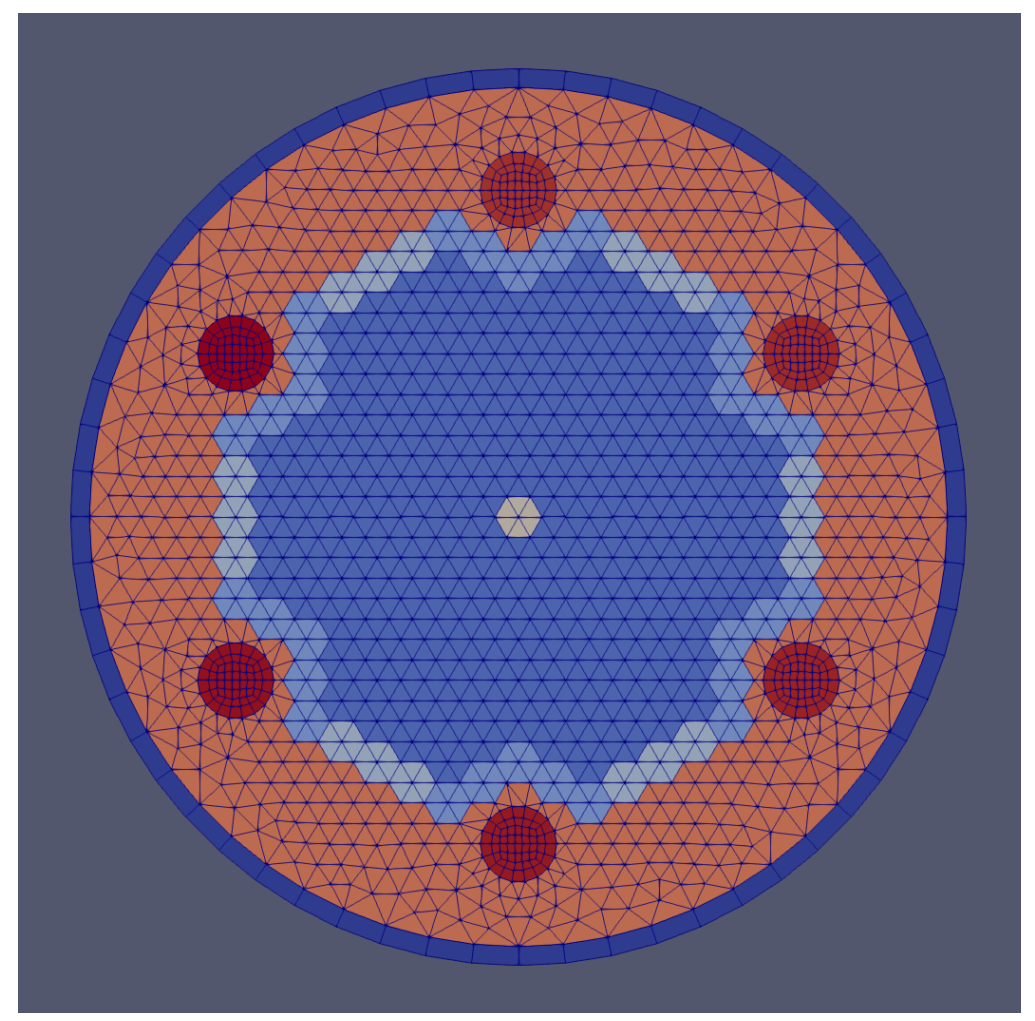

Figure 13 MAMMOTH homogenized finite element mesh. 
For MAMMOTH to generate SPH equivalence factors, the Serpent calculation must provide a reference flux distribution for regions of the mesh denoted by equivalence ID's. It is straightforward to have Serpent tally fluxes for lattice hex elements and for discrete material regions. Consequently, the regions for which a reference flux solution is provided and SPH factors generated is the subset of the mesh depicted in Figure 14. In addition to the 192 fuel elements, SPH factors are also calculated for the 36 hexes in the first row of the side reflector and for the six control drums.

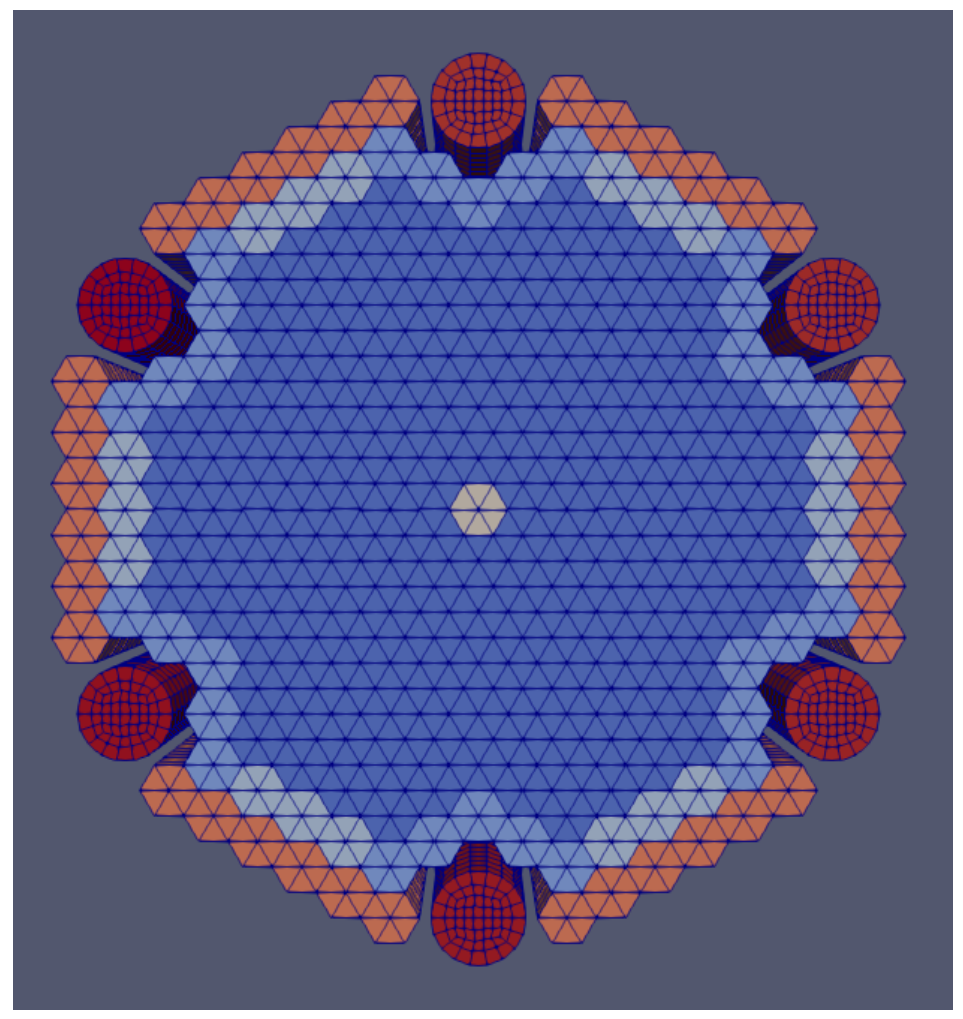

Figure 14 Portion of MAMMOTH mesh for which SPH factors are calculated.

Table 9 Meshing parameters for the MAMMOTH model

\begin{tabular}{|l|c|c|c|}
\hline Material Region & $\begin{array}{c}\text { Length } \\
(\mathbf{c m})\end{array}$ & $\begin{array}{c}\text { Number of } \\
\text { Axial Elements }\end{array}$ & $\begin{array}{c}\text { Number of } \\
\text { Equivalence Zones }\end{array}$ \\
\hline Support Plate & 5 & 1 & 1 \\
\hline Bottom Reflector & 15 & 3 & 3 \\
\hline Bottom of Fuel & 10 & 2 & 2 \\
\hline Central Fuel & 80 & 16 & 8 \\
\hline Top of Fuel & 10 & 2 & 2 \\
\hline Top Reflector & 15 & 3 & 3 \\
\hline
\end{tabular}


A simple swept mesh is used for the axial discretization as detailed in the table above for a fuel element. A uniform axial element size of $5 \mathrm{~cm}$ was used for this demonstration model for a total of 27 axial levels. Note that the fueled region is split into 3 different zones (top, center and bottom) to better account for the spectral shift seen by the fuel near the axial $\mathrm{BeO}$ reflectors. In summary, for six axial material regions there are a total of 19 equivalence zones and 27 axial levels for a single fuel element. The axial meshing and number of equivalence zones is the same for both the side reflector hexes and the control drums, as is listed in Table 9.

\subsubsection{Reactivity feedback effects}

For sodium-cooled fast reactors (SFR), the primary reactivity feedback effects during a transient heat up event in approximate order of importance are:

- Radial Expansion (negative): increased core inlet temperature causes thermal expansion of the core diagrid thereby increasing the fuel assembly pitch and axial neutron leakage.

- Fuel Axial Expansion (negative): decreased fuel density and higher core height resulting in increased radial neutron leakage.

- Coolant Density (positive or negative): two competing effects as reduced sodium density causes less scattering thereby hardening the spectrum (positive effect) and increasing neutron leakage (negative effect). Net effect depends on design.

- Doppler (negative): increased neutron absorption in resonance region due to broadening of absorption cross-section peaks. Note this is considerably less important than for typical LWRs.

- Control Rod Drive Line Expansion (negative): expansion of the drive line effectively increases control rod insertion depth providing a negative reactivity feedback.

Thus, for SFR analysis, a typical approach would be to parameterize the macroscopic crosssections as functions of:

- Fuel temperature

- Sodium density

- Burnup

- Average fuel assembly pitch (radial expansion)

- Average core height (axial expansion)

- Control rod worth

Most micro-reactor designs aim for low burnup and so that effect has been ignored for this demonstration calculation. Also, due to the nature of a heat pipe-cooled micro-reactor, there is little fluid "coolant" and so its density effect has likewise been ignored. Also, as the selected transient will be an unprotected heat up, we will consider both the shutdown control rod and the control drums to remain in their initial critical configuration and so have not undertaken the effort to parameterize the cross-sections with respect to control rod (drum) position. Therefore, the reactivity feedback effects considered here will be limited to the doppler effect, radial expansion and axial expansion. 
For the coupled MAMMOTH/SAM calculation, the reactivity effects due to thermal expansion will not be modeled through parameterization of the cross-sections as one would typically do with a legacy code. Rather, the ability of MAMMOTH as a MOOSE-based code to use a displaced mesh will be utilized. That is, the finite element mesh will deform during the transient corresponding to the strains calculated by the MOOSE Tensor Mechanics submodule. As MAMMOTH automatically considers the effect of material density changes on the macroscopic cross-sections due to mesh deformation, both the geometry and density effects can be handled without the need for geometry parameterization of the cross-sections. This greatly simplifies the cross-section preparation part of this endeavor as only the dependence on fuel temperature need be considered. Indeed, for this demonstration analysis only two state points were calculated, fuel temperature at 900 and $1200 \mathrm{~K}$.

Reference values for these three parameters were obtained from the nominal $900 \mathrm{~K}$ steadystate conditions using Serpent as follows:

- Doppler: perturb the fuel and structure temperature by $100 \mathrm{~K}$.

- Radial Expansion: calculate the radial expansion of the core support plate for a $100 \mathrm{~K}$ temperature increase and project this radial expansion uniformly throughout the core. This represents an increase in the core diameter of $2.48 \mathrm{~mm}$.

- Axial Expansion: calculate the axial expansion of the heat pipe wall for a $100 \mathrm{~K}$ temperature increase and expand the core axially uniformly. This represents an increase in the core height of $2.82 \mathrm{~mm}$.

The resulting reactivity feedback coefficients are listed in Table 10.

Table 10 Reactivity feedback coefficients

\begin{tabular}{|l|c|}
\hline \multicolumn{2}{|c|}{ Reactivity Feedback Coefficients [pcm/K] } \\
\hline Doppler Effect & -0.320 \\
\hline Axial Expansion & -0.905 \\
\hline Radial Expansion & -1.349 \\
\hline Combined Effect & -2.540 \\
\hline
\end{tabular}

The MAMMOTH deformable mesh capability has been used previously for numerical benchmarks such as the Godiva experiment [Wang et al. 2017]. However, applying it to a full micro-reactor core simulation does represent a "first of a kind" analysis. To ensure the accuracy of this approach, a series of verification tests were run. In these, MAMMOTH served as the master app while a "dummy" sub app was used to feed back the relevant temperature changes or mesh displacements. Then the Serpent reference calculations noted above were simulated with MAMMOTH and the comparative eigenvalue results are given in Table 11.

As the differences of only a few pcm between the Serpent reference values and the MAMMOTH calculations are the same magnitude as the uncertainty in the Serpent values 
themselves, these results can be considered excellent and a verification of the MAMMOTH approach for handling the reactivity effects due to thermal expansion.

Table 11 Comparison of Serpent2 and MAMMOTH results

\begin{tabular}{|l|c|c|c|}
\hline \multicolumn{1}{|c|}{ Case } & $\begin{array}{c}\text { Serpent2 } \\
\left.\text { Value (uncertainty }{ }^{2}\right)\end{array}$ & MAMMOTH \\
\hline Base & $0.999969\left(3.6 \times 10^{-5}\right)$ & 0.9999969 & $\sim 0$ \\
\hline Doppler Effect & $0.999649\left(3.4 \times 10^{-5}\right)$ & 0.999681 & -3.2 \\
\hline Axial Expansion & $0.999064\left(3.6 \times 10^{-5}\right)$ & 0.999113 & -4.9 \\
\hline Radial Expansion & $0.998620\left(3.3 \times 10^{-5}\right)$ & 0.998624 & -0.4 \\
\hline Combined & $0.997429\left(3.4 \times 10^{-5}\right)$ & 0.997481 & -5.2 \\
\hline
\end{tabular}

\subsection{Modeling of heat conduction with SAM}

The 3D whole-core model for modeling the heat conduction in the reactor core is shown in Figure 15. The 3D mesh for the heat conduction calculation is shown in Figure 16. To ensure the accuracy of the simulation, second-order mesh is used. The empty space inside each fuel assembly is where the heat pipes are located. They are omitted in the heat conduction calculation. For the heat conduction calculation, the reactor core consists of several different regions of different materials as explained below:

- Stainless steel: support plate, hex can, and reactor vessel

- U-10Zr: fuel

- BeO: lower and upper reflector

- A12O3: side reflector

- Pseudo gas: central control rod space

For simplifications, the control drum is removed in the model and replaced with the side reflector. Because the central assembly will be used as the control rod system, it will be modeled as a region of pseudo gas. An effective thermal conductivity of $2.232 \mathrm{~W} /(\mathrm{m} \mathrm{K})$ is used for the pseudo gas.

2 As a Monte Carlo code, Serpent provides uncertainty estimates for its calculated quantities. These uncertainties are relative. However, as the values of the eigenvalues are essentially unity, an uncertainty of $3.6 \times 10^{-5}$ corresponds to an uncertainty of $3.6 \mathrm{pcm}$. 

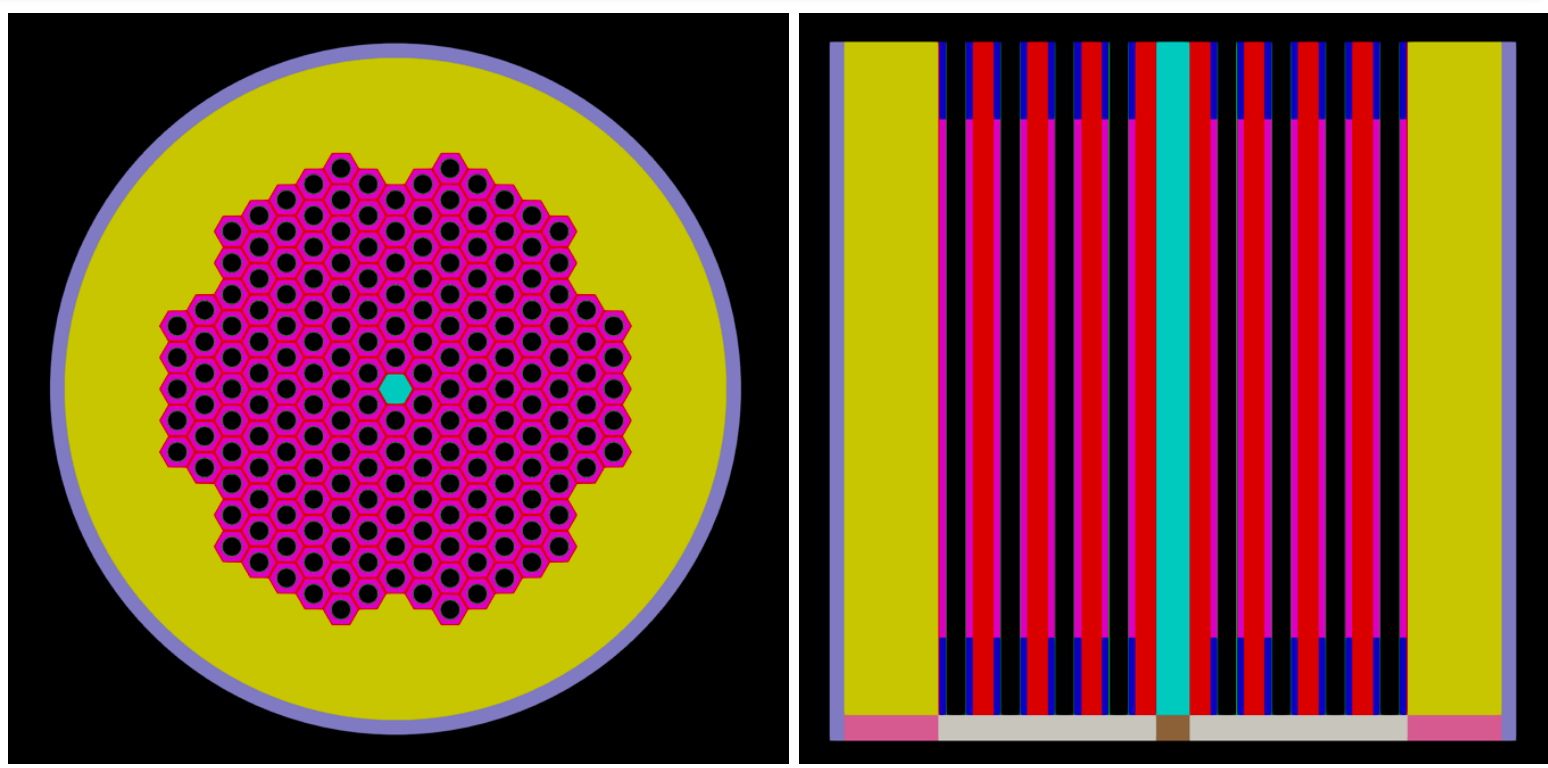

Figure 15 The heat pipe micor reactor 3D heat conduction model. Left: top view; Right: front view
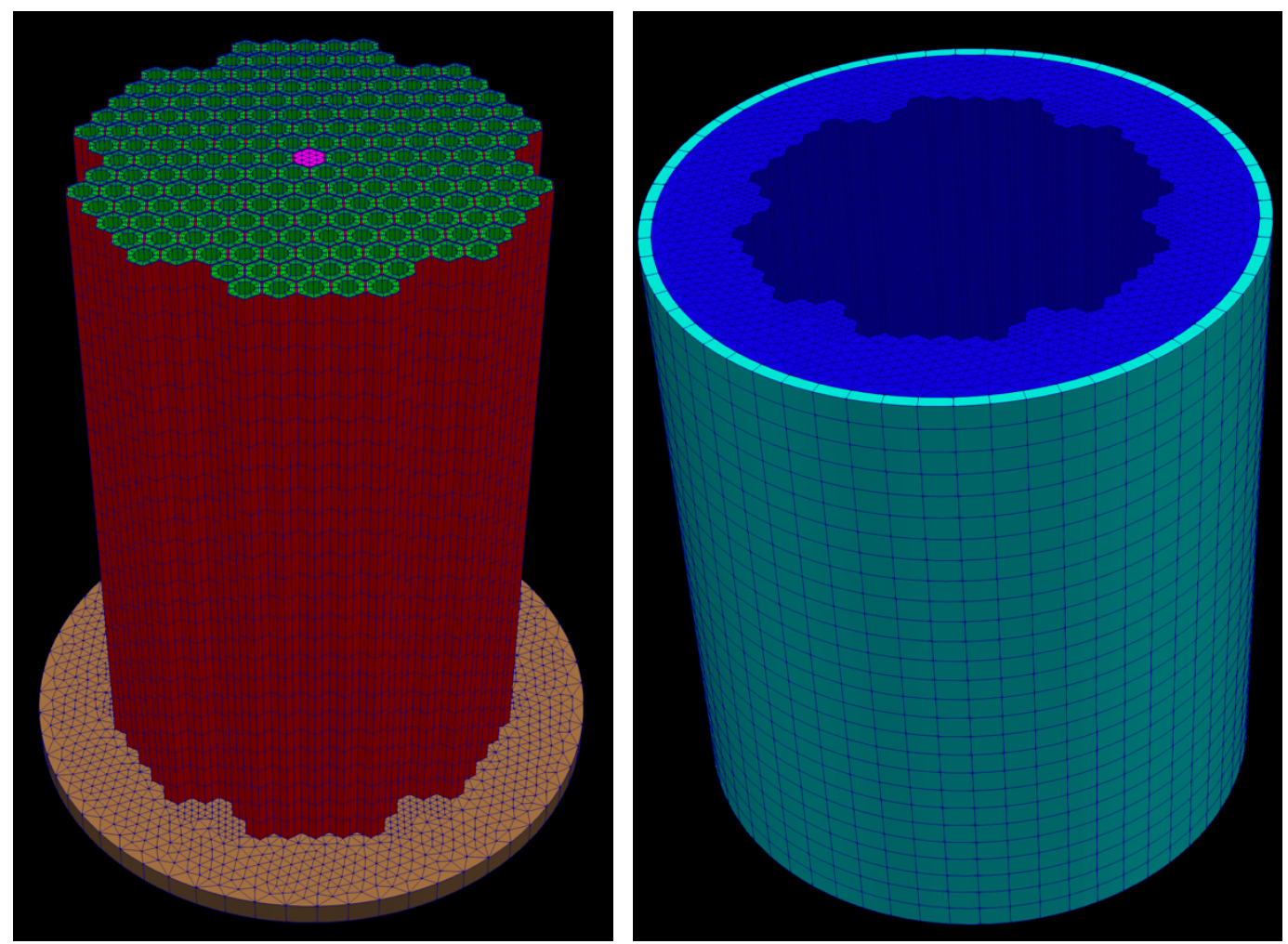

Figure 16 3D mesh for the heat conduction in the reactor core. Left: support plate, hex can, fuel, lower/upper reflector, central control space. Right: side reflector and reactor vessel

The boundary conditions are specified at 3 different surfaces:

- The surface between the fuel/reflector and the heat pipe wall: a convective boundary condition is applied using the heat pipe wall surface temperature and an effective heat 
transfer coefficient of $10^{5} \mathrm{~W} /\left(\mathrm{m}^{2} \mathrm{~K}\right)$. A very high heat transfer coefficient is used to simulate a very small thermal resistance. This surface is used to couple the HC and HPs.

- The reactor vessel outer surface: a radiation boundary condition is applied using the wall temperature of the solid wall in the RCCS system. As the design details of RCCS are not available, a view factor of 1 and emissivity of 1 (for both surface) are used in the demo calculation. This surface is used to couple the HC and the RCCS.

- The top and bottom of the reactor core: a convective boundary condition is applied using an ambient temperature of $700 \mathrm{~K}$ and an ad-hoc effective heat transfer coefficient of $10 \mathrm{~W} /\left(\mathrm{m}^{2} \mathrm{~K}\right)$. The effective heat transfer coefficient is set to be small indicating the little heat would be transported out from these surfaces.

\subsection{Modeling of secondary heat exchanger with SAM}

In the current reactor core design, the heat pipes are assumed to extend from the support plate, through the lower reflector, fuel, upper reflector, upper shield (if any), and into the secondary heat exchanger. For simplicity, the heat exchanger is assumed to have an axial flow configuration, as shown in Figure 17. The coolant supply enters into a lower plenum at the bottom, flows up through the individual coolant annuli, into an upper plenum, and exit to the power conversion system.

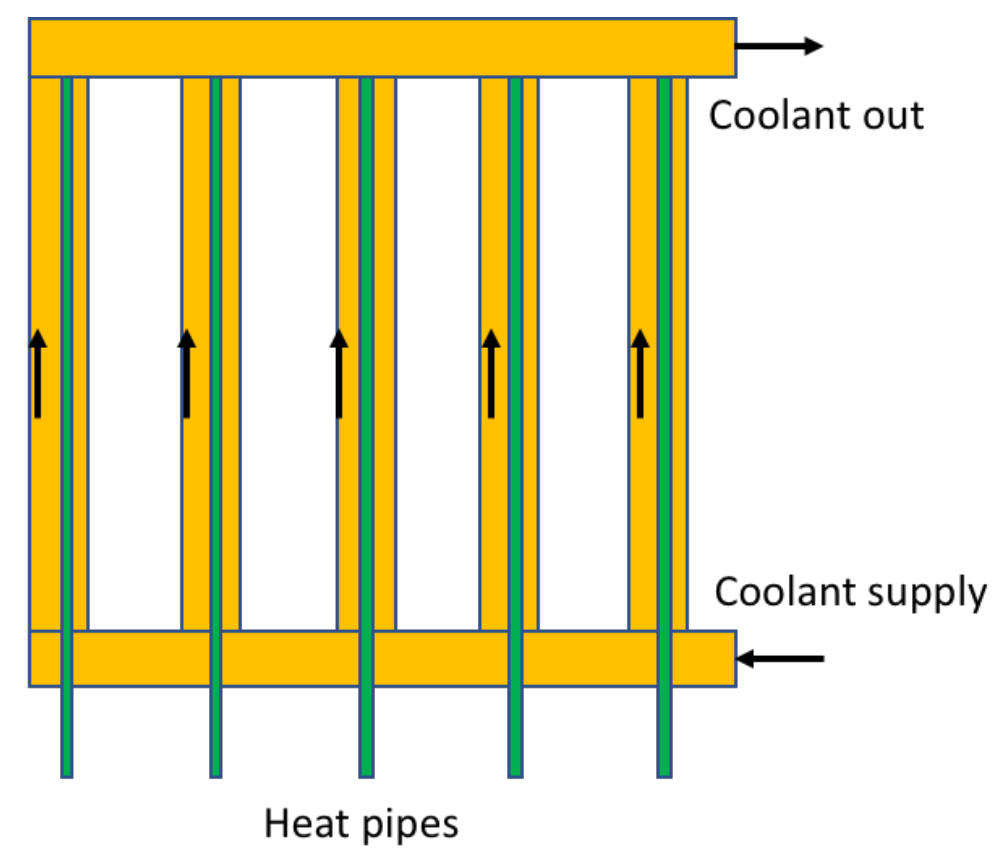

Figure 17 Simplified heat pipe heat exchanger 


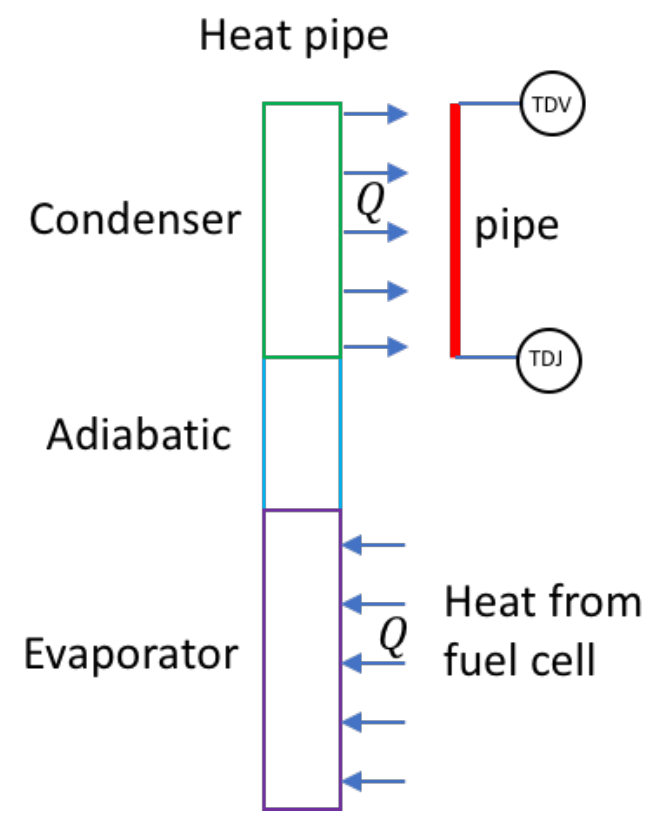

Figure 18 Simplified model of secondary heat exchanger in SAM

Figure 18 shows schematically the simplified model of the secondary heat exchanger in SAM. In the current scheme, the secondary heat exchanger is modeled by attach each individual heat pipe with a cooling pipe. For simplification purposes, the coolant in the lower plenum is assumed to be well mixed, the boundary conditions for the individual heat pipe are thus the same. However, the boundary conditions for the individual cooling pipe can be adapted to realistic conditions later if the working details of the secondary heat exchanger are available. The inlet velocity and temperature of the cooling pipe are set, in an ad-hoc way, at $1.0 \mathrm{~m} / \mathrm{s}$ and $750 \mathrm{~K}$, respectively.

For each individual heat pipe, the evaporator wall surface is coupled with the respective fuel cell and takes the heat through conduction. The condenser wall surface is coupled with the cooling pipe and deposits the heat to the cooling pipe through convective heat transfer. Since the coupling between the evaporator wall and the fuel cell is achieved through MOOSE's MultiApp system, a nonlinear iteration between the HC and HPs is required, which is achieved through the Picard iteration.

\subsection{Modeling of reactor cavity cooling system (RCCS) with SAM}

The details of the RCCS for the heat pipe micro reactor design are not available, the RCCS will be simplified to a solid wall coupled with a cooling pipe, as is shown in Figure 19. The left side of the solid wall is coupled with the reactor vessel through radiation heat transfer; while its right side is coupled with the cooling pipe. This rather simplified modeling approach is aimed to demonstrate the capability of current multi-physics simulation methodology instead of a design simulation. Once the design details are available, the model can be adapted with little effort. As noted, the left side of the solid is coupled with the reactor vessel through the MultiApp system. Thus, a nonlinear iteration between the core heat conduction (HC) and the RCCS is required, which is done through the Picard iteration. The inlet velocity and inlet coolant temperature of the cooling pipe are set, in an ad-hoc way, at $1.0 \mathrm{~m} / \mathrm{s}$ and $300 \mathrm{~K}$, respectively. 


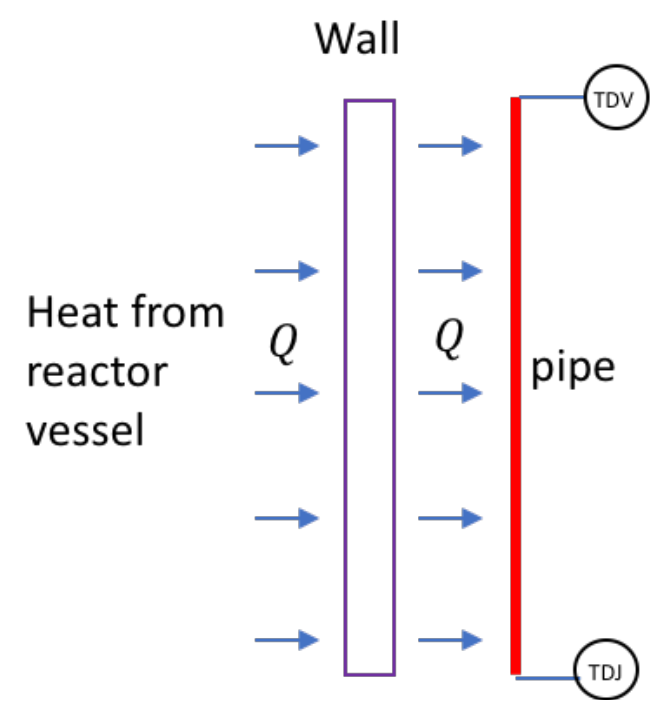

Figure 19 Simplified model of reactor cavity cooling system in SAM

\subsection{Modeling of axial expansion with Tensor Mechanics}

Figure 20 shows schematically the simplified model for modeling the axial expansion of fuel cell in Tensor Mechanics. The current fuel axial expansion model assumes that there is no interaction between different fuel cells, thus the axial expansion calculation of each individual fuel cell can be separated from each other and potentially simulated in parallel. As noted in Figure 20, the model consists of a support plate block, a fuel block, and a heat pipe wall block. The bottom and top reflector are omitted based on the assumption that reflector material expands much smaller than the fuel and heat pipe wall. The material of the heat pipe wall is chosen such that the thermal expansion of heat pipe wall is larger than the fuel, thus the fuel and the heat pipe wall are bonded together in normal operation condition. Under this condition, the axial expansion of the fuel is mainly determined by the heat pipe wall. The boundary conditions are applied at the support plate. The bottom surface of the support plate is assumed to be fixed. A rough estimate of the average fuel temperature (about $915 \mathrm{~K}$ ) is used as the stress-free temperature.

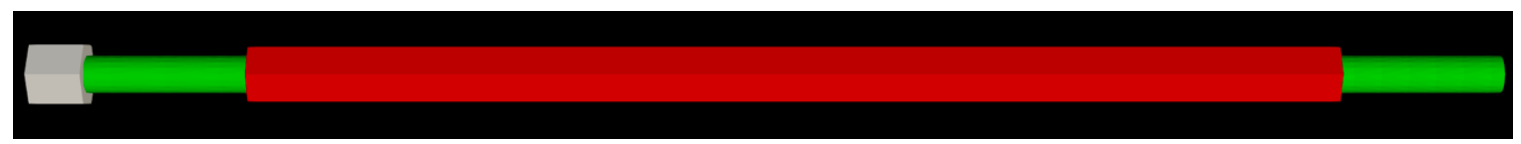

Figure 20 Simplified model for axial expansion of fuel cell in Tensor Mechanics

\subsection{Modeling of radial expansion with Tensor Mechanics}

Figure 21 shows schematically the simplified model for modeling the radial expansion of the reactor core in Tensor Mechanics. The radial expansion of the reactor core is assumed being determined by the radial expansion of the support plate. Thus, the model consists of only the support plate. The support plate takes the temperature field from the $\mathrm{HC}$ model and return the 
displacement field to the RK model for reactivity calculation. A rough estimate of the average support plate temperature (about $818 \mathrm{~K}$ ) is used as the stress-free temperature.

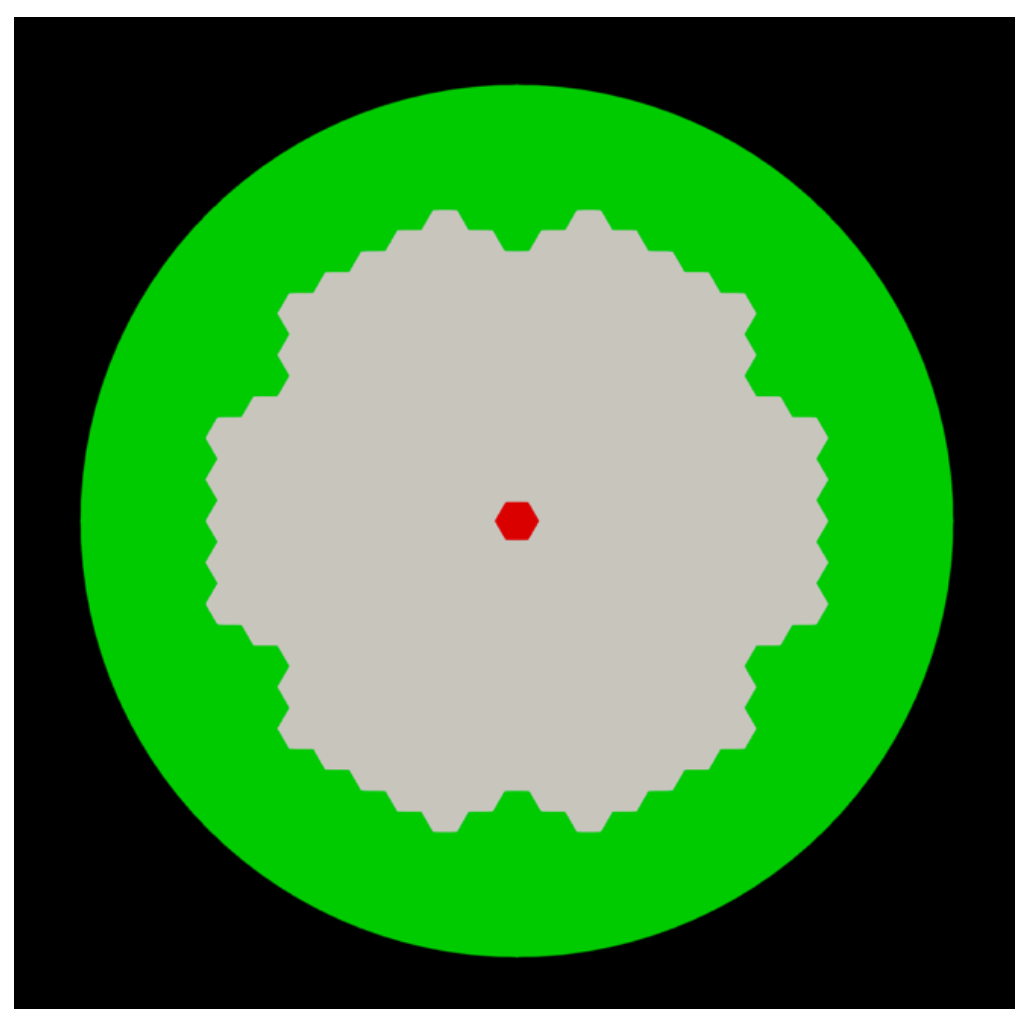

Figure 21 Simplified model for reactor radial expansion in Tensor Mechanics 


\section{Demonstration Results}

In this chapter, the multi-physics coupling model will be demonstrated by performing a steadystate operation analysis and transient simulations of a single heat pipe failure and an unprotected loss of heat sink event. Since many design details of the heat pipe micro reactors are not available, made up parameters are used extensively in the following analysis.

\subsection{Steady state analysis}

Several key parameters at the steady state will be analyzed in detail below, including the power density distribution, solid temperature in the reactor core, average fuel temperature in different fuel cells, heat pipe removal rate of different heat pipes, fuel axial expansion, and plate radial expansion. Table 12 lists several of the main parameters from the steady state simulation. Note that the eigenvalue is $k_{e f f}=0.99990477$. The cross-section preparation is based on the assumption of un-deformed geometry and uniform fuel temperature; however, the coupled steady state simulation does consider the deformed geometry and the non-uniform fuel temperature. This difference caused the negative reactivity. The effect of this negative reactivity will be studied in the later transient analysis section.

Table 12 Main parameters in steady state simulation

\begin{tabular}{|l|l|}
\hline Parameters & Value \\
\hline Eigenvalue & 0.99990477 \\
\hline Total power & $5.0 \mathrm{MW}$ \\
\hline Power to heat pipes & $4.8942 \mathrm{MW}$ \\
\hline Power to RCCS & $0.05291 \mathrm{MW}$ \\
\hline Average fuel temperature & $914.681 \mathrm{~K}$ \\
\hline Average hex can temperature & $912.856 \mathrm{~K}$ \\
\hline Average bottom/top reflector temperature & $866.903 \mathrm{~K}$ \\
\hline Average side reflector temperature & $765.625 \mathrm{~K}$ \\
\hline Average plate temperature & $803.571 \mathrm{~K}$ \\
\hline Average vessel wall temperature & $674.478 \mathrm{~K}$ \\
\hline
\end{tabular}

Figure 22 and Figure 23 show the cross-sectional view of the solid temperature profile in the reactor core. Figure 24 shows the average fuel temperature in different fuel cells. The distribution of the average fuel temperature keeps very well the symmetry of the reactor core.

Figure 25 shows quantitively the heat removal rate of the individual heat pipes. It is seen that the profile is closely following that of the power density of individual fuel cell. The heat pipe heat removal rate near the center of the core is about 1.5 times of that near the periphery of the core. 


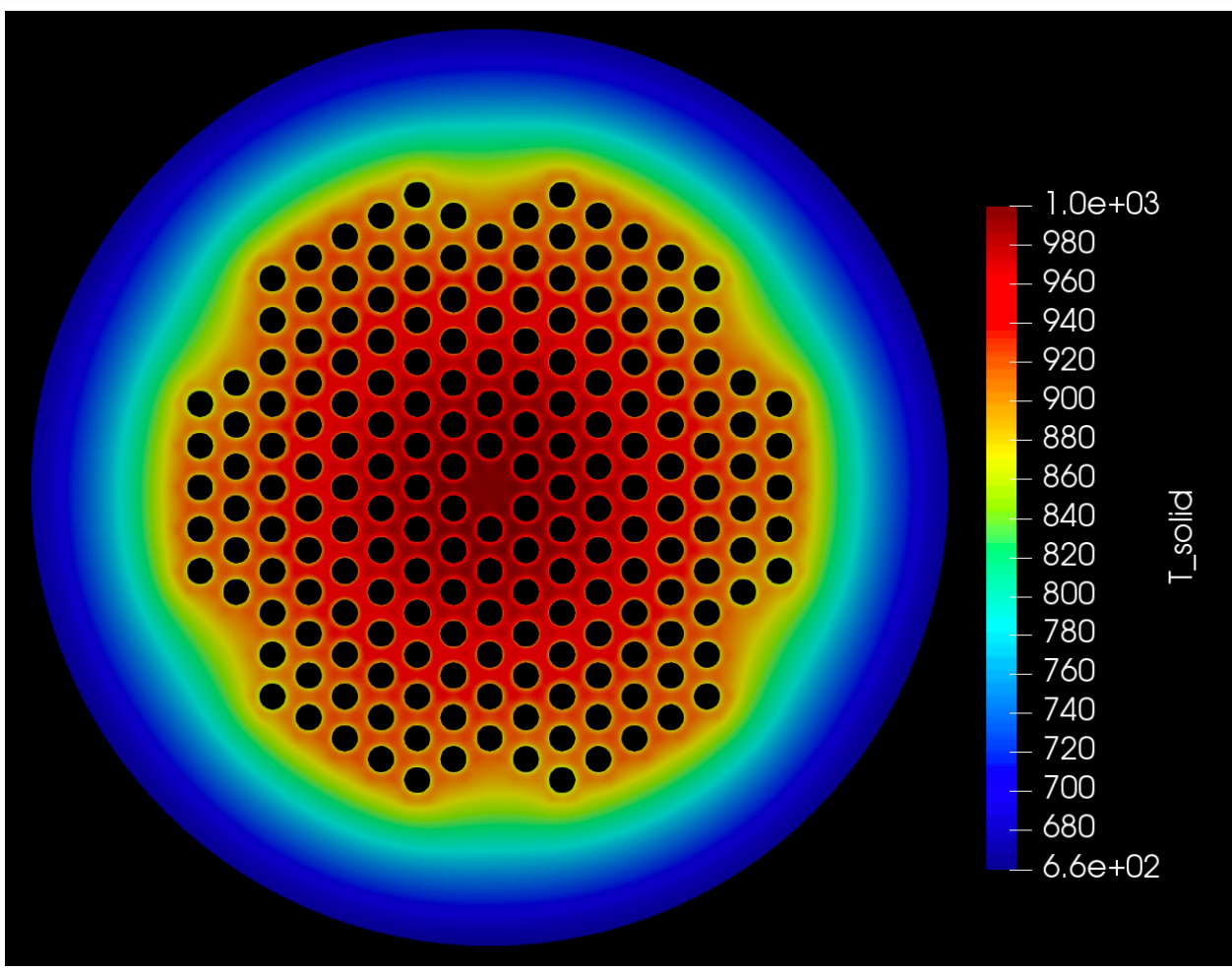

Figure 22 Steady state solid temperature profile. Horizontal cut view.

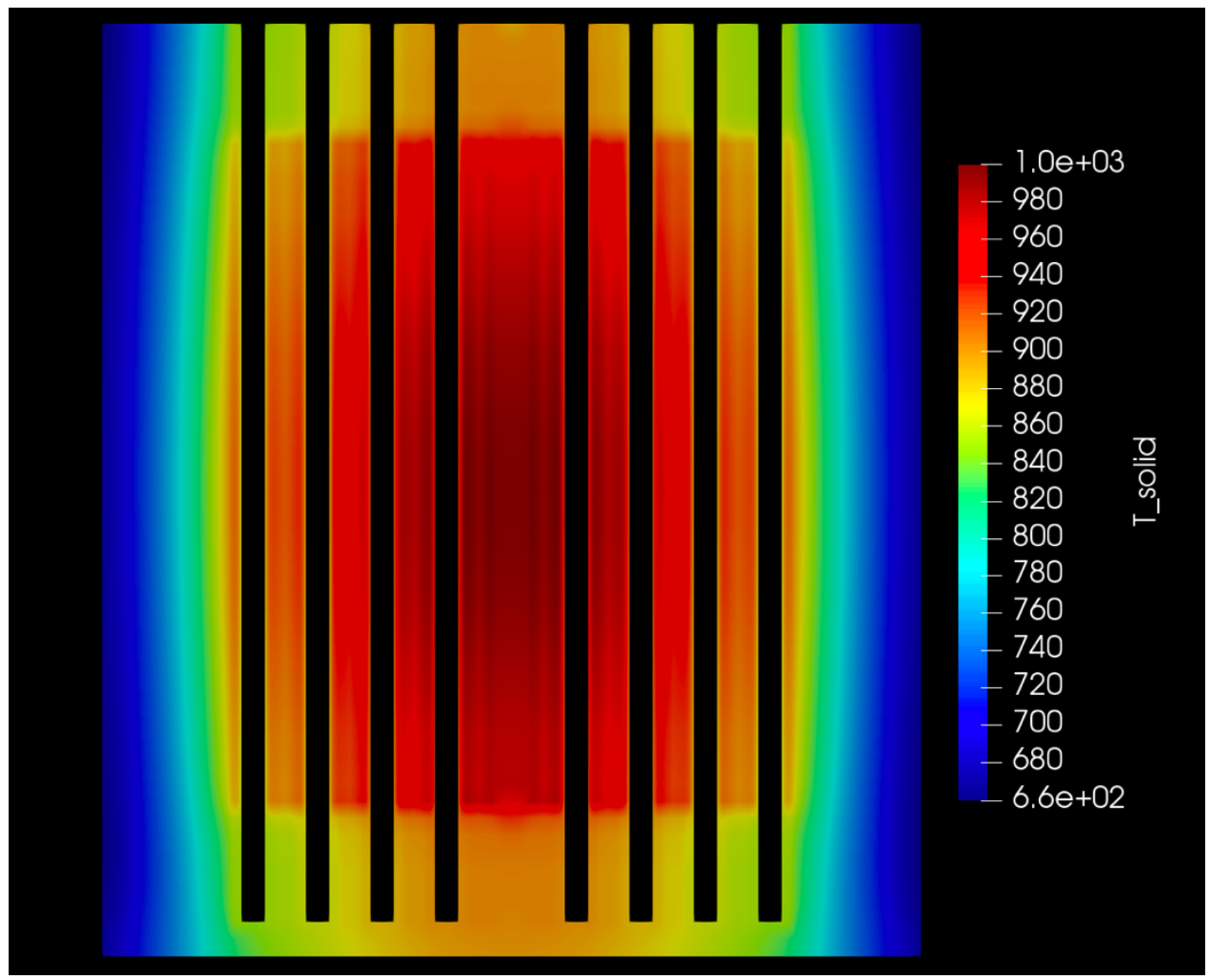

Figure 23 Steady state solid temperature profile. Vertical cut view. 


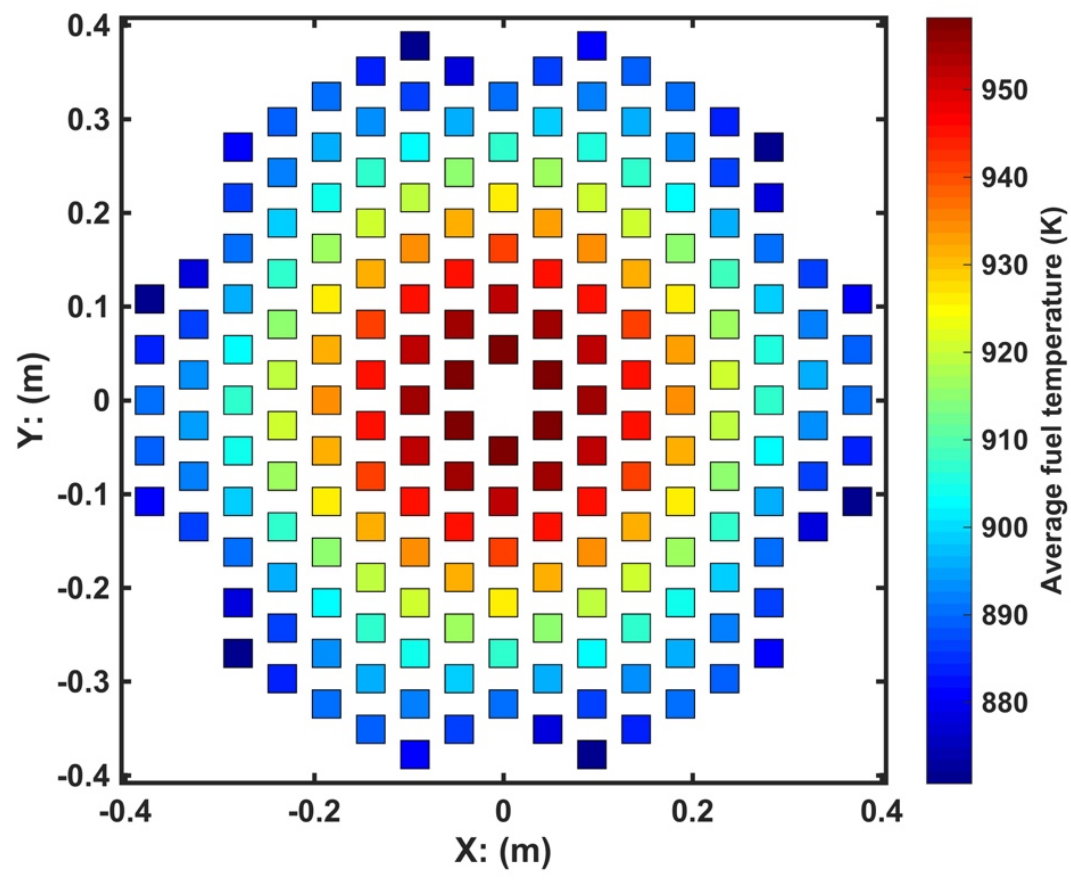

Figure 24 Distribution of average fuel temperature at different fuel cells

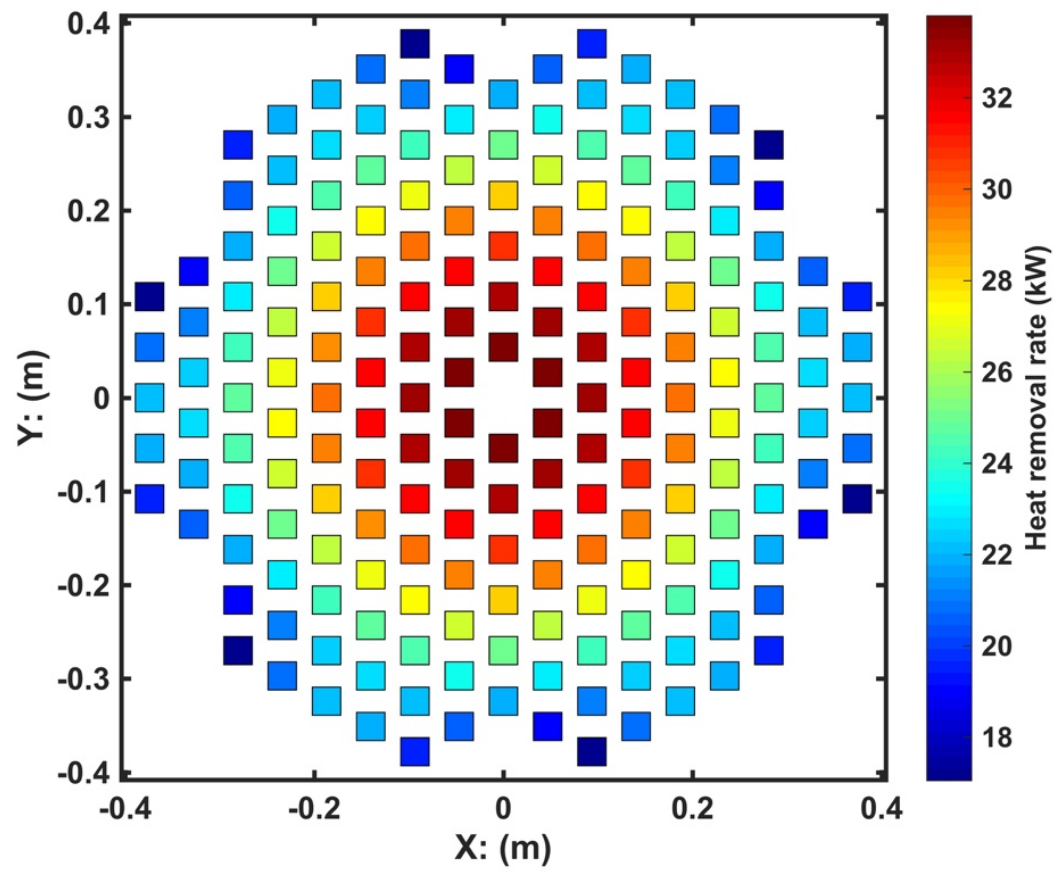

Figure 25 Distribution of heat removal rate through different heat pipes

Figure 26 shows the fuel axial expansion in different fuel cells. Note that the fuel axial expansion is positive at the center of the reactor core while negative near the periphery of the reactor core. This is because the average fuel temperature in the whole core is used as the stress- 
free temperature in the tensor mechanics model. The axial displacement given by the tensor mechanics calculation represents the relative instead of absolute displacement. This modeling approach may need to be re-evaluated in the future.

Figure 27 shows the distribution of the radial displacement in the plate. The average plate temperature is provided to the tensor mechanics model as the stress-free temperature. Near the center of the core, the plate temperature is higher than the average temperature; while near the periphery of the core, the plate temperature is lower than the average temperature. From the center to the periphery of the core, it is seen that the radial displacement is at first increasing and then decreasing. Again, this is caused by the use of average plate temperature as the stress-free temperature. This modeling approach may need to be re-evaluated in the future.

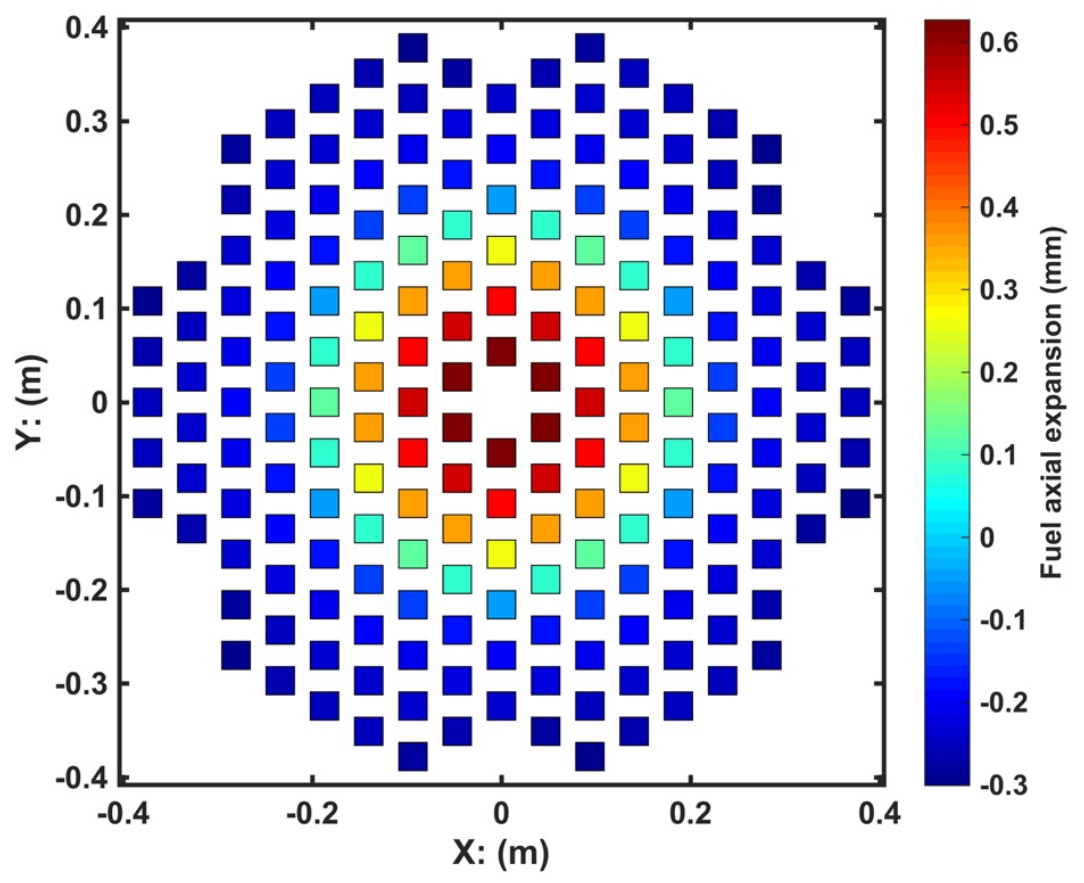

Figure 26 Distribution of fuel axial expansion at different fuel cells
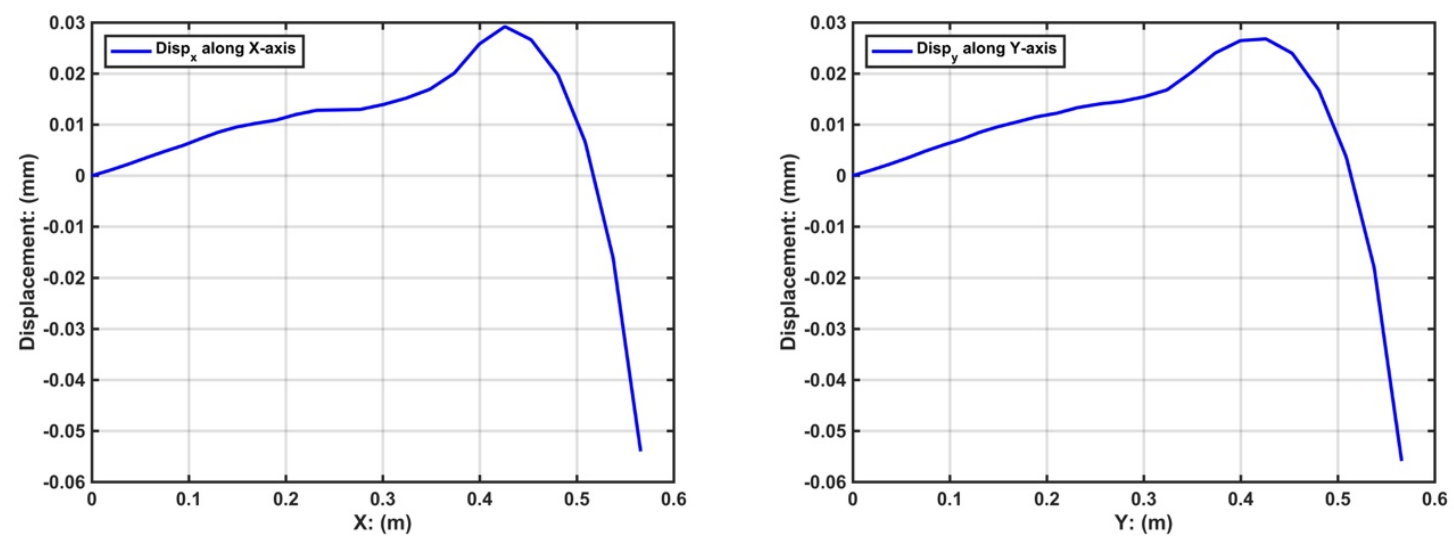

Figure 27 Radial expansion in the plate. Left: $x$-displacement along the $x$-axis; Right: $y$ displacement along the $y$-axis 


\subsection{Transient analysis}

\subsubsection{Simulation work flow}

The reactivity feedback effects considered here will be limited to the doppler effect, radial expansion and axial expansion. In this demonstration test, the shutdown control rod and the control drums are assumed to remain in their initial critical configuration, thus we have not undertaken the effort to parameterize the cross-sections with respect to control rod (drum) position.

In the current cross-section preparation effort, an undeformed geometry and a uniform fuel temperature of $900 \mathrm{~K}$ is used. The uncoupled RK calculation shows that the eigenvalue is $k_{\text {eff }}=$ 0.9999969. However, there is a difficulty in obtaining the critical configuration when considering the deformed geometry and the non-uniform fuel temperature distribution. When the RK model is coupled with the heat conduction and tensor mechanics model, an extra negative reactivity is introduced to the system, which gives a subcritical configuration. For example, the coupled calculation shows that the eigenvalue of the system is $k_{e f f}=0.99990477$. The control drum needs to be adjusted to compensate for this negative reactivity. However, this adjustment is not an easy task since it requires the iterations between the cross-section preparation and the coupled eigenvalue calculation. An alternative approach is used to address this issue.

The idea is to use a null transient simulation to get the steady state of the system. The reactivity feedbacks due to the Doppler effect, radial expansion, and axial expansion are expected to compensate for the initial negative reactivity during the null transient simulation. Once the reactor power and reactor temperatures are stabilized, we can then perform the designed transient analysis. A schematic of the approach is shown in Figure 28. The simulation is split into 3 steps.

1. Step 1: a steady-state simulation will be performed in this step, where the different submodels are coupled together. In this simulation, the RK model performs the eigenvalue calculation and then calculates the power density based on the assigned total power ( 5 MW); the HC model (coupled with HP and VCCS model) takes the power density from RK model and calculate the reactor temperature; the TM models takes the reactor temperatures from $\mathrm{HC}$ model and calculate the radial and axial expansion of the grid plate and fuels, respectively. The reactor core temperature, radial expansion of the plate, and axial expansion of the fuel will be transferred to the RK model and saved for next step. In this step, the convergence criterion for the coupled simulation can be loose.

2. Step 2: the coupled model is restarted from the saved state in the previous simulation step. The simulation is switched to the transient execution mode, but the physical and boundary conditions of the system are not changed. The reactivity feedback due to the Doppler effect, radial expansion, and axial expansion are considered by the RK model. During this simulation, the total power of the system is changing over time and is expected to stabilize to a constant value. Once the system is stabilized, we can proceed to the next step for a transient analysis.

3. Step 3: following the end of the step 2, a transient event is introduced to the system for a transient analysis. 


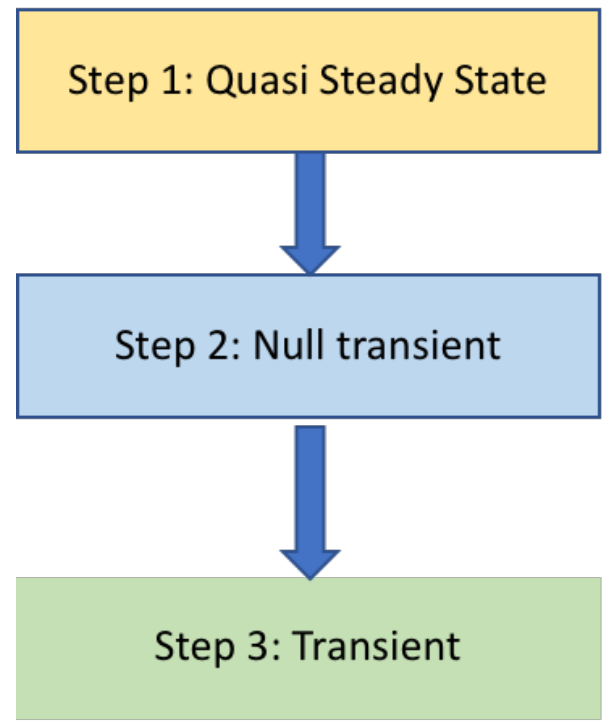

- Eigenvalue

- Power density

- Reactor core temperature

- Reactivity feedback

- Heat pipe operation state

- RCCS operation state

- Operation power

- Reactor core temperature

- Heat pipe operation state

- RCCS operation state

- Power history

- Reactor core temperature

- Heat pipe heat removal rate

- RCCS heat removal rate

Figure 28 Transient analysis work flow and quantity of interest

\subsubsection{Null transient: effect of initial negative reactivity}

In this test, a null transient simulation is performed to study the effect of initial negative reactivity caused by the non-uniform temperature distribution in the reactor core. The main quantity is the total reactor power, which is expected to stabilize in the end of the null transient.

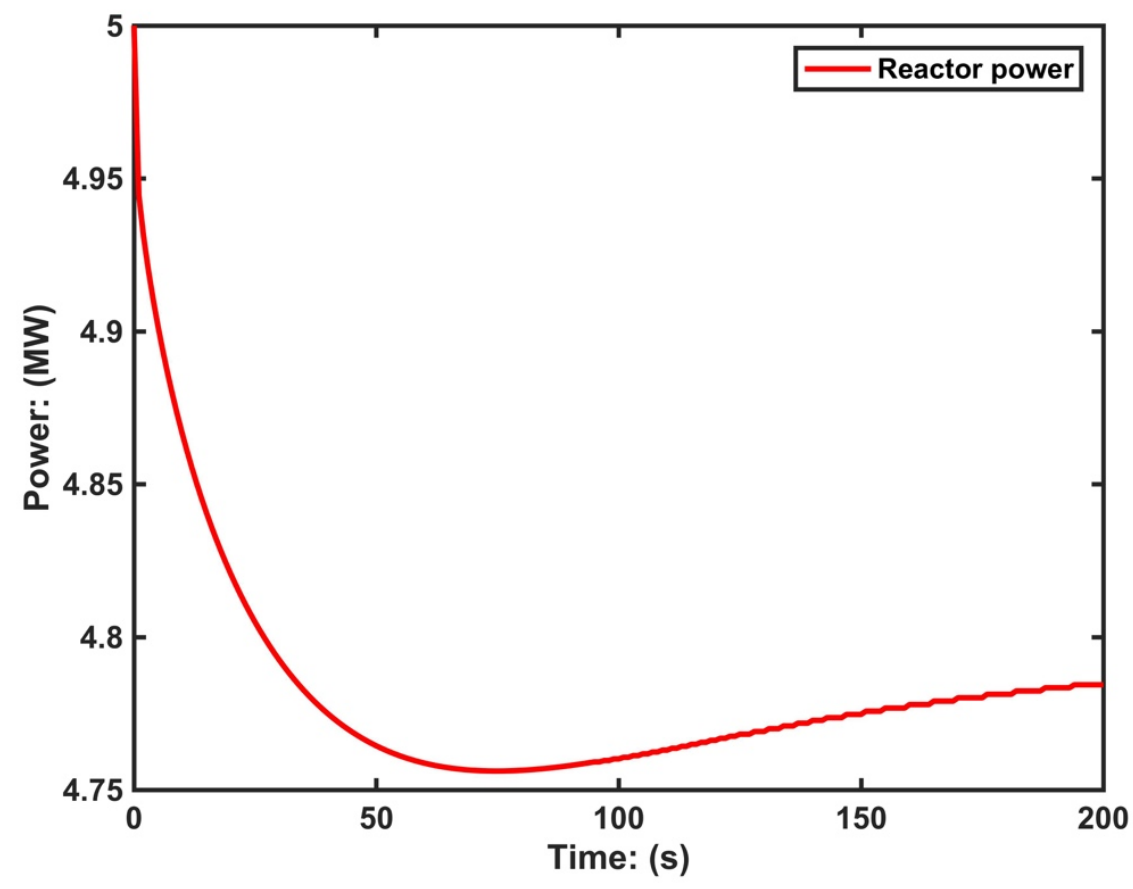

Figure 29 History of total power in the null transient simulation 


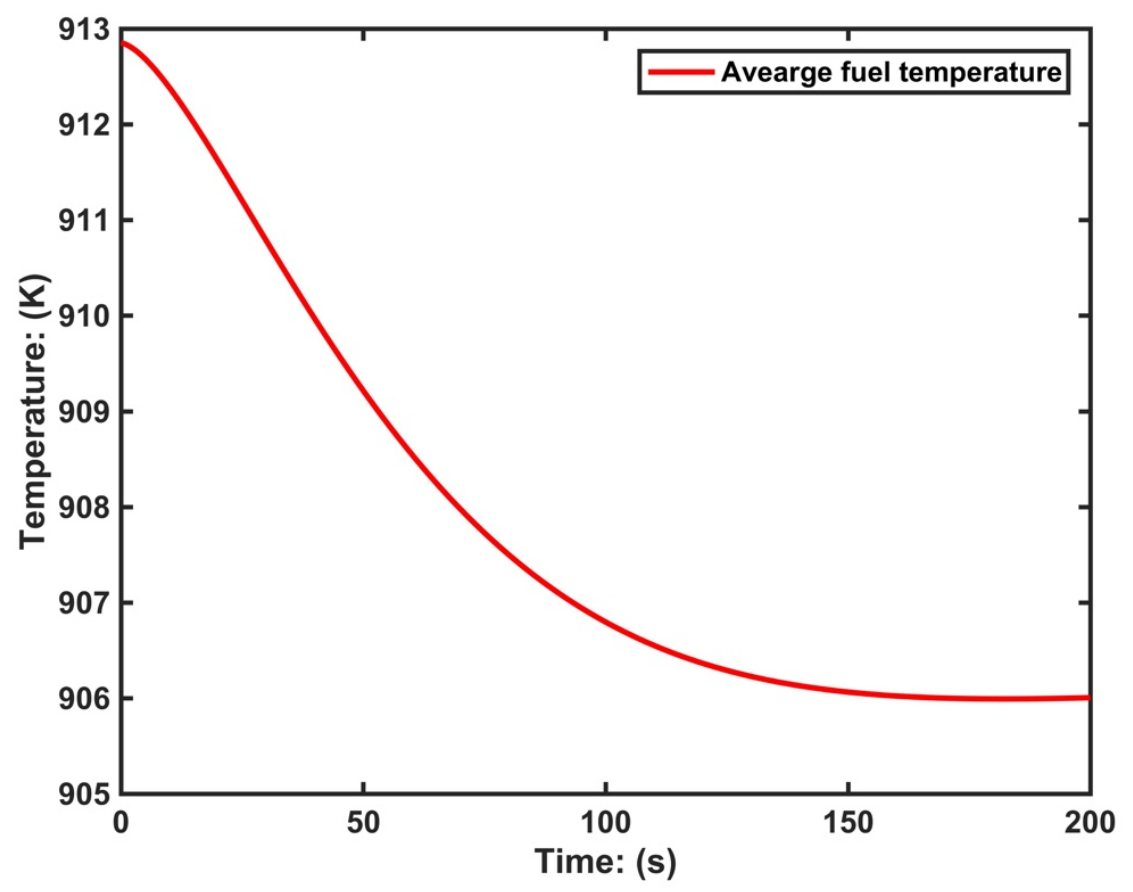

Figure 30 History of average fuel temperature in the null transient simulation

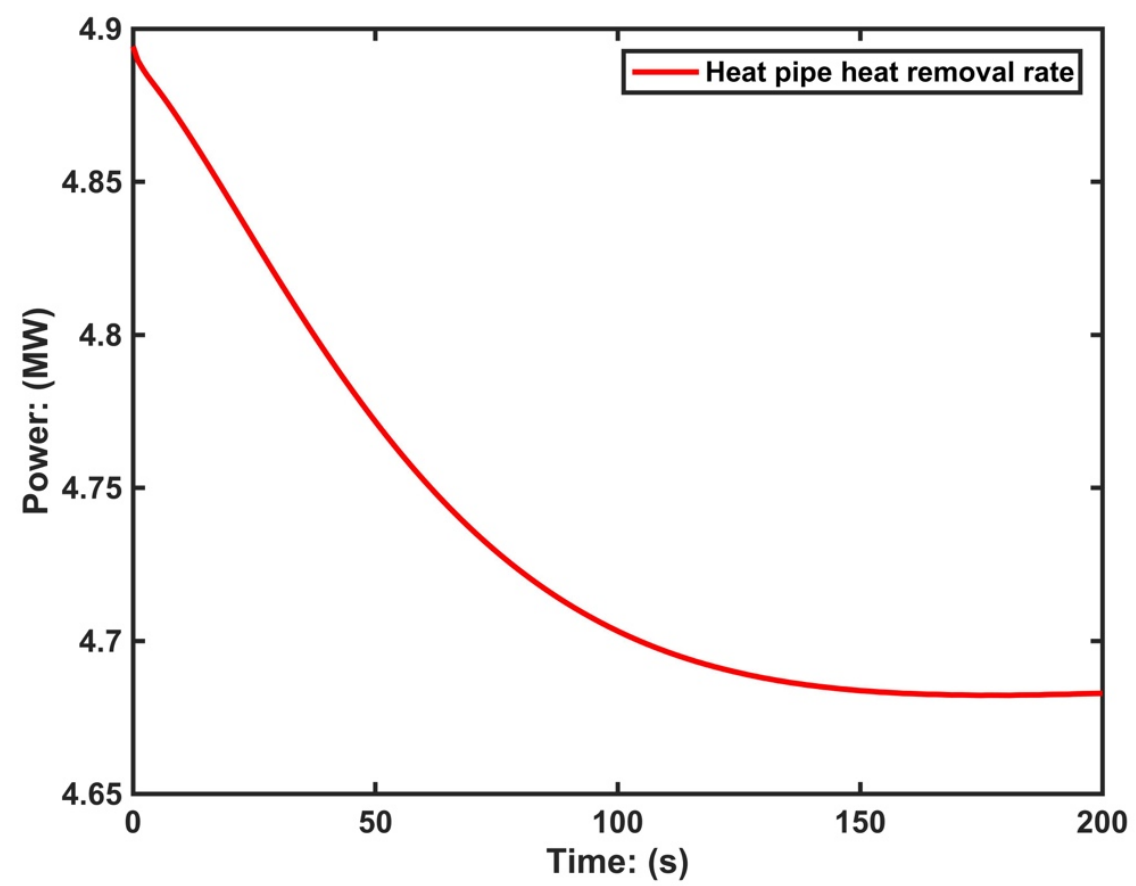

Figure 31 History of heat pipe heat removal rate in the null transient simulation

The results of the null transient simulation are shown in Figure 29, Figure 30, and Figure 31, where the power history, average fuel temperature, and heat pipe heat removal rate during the null 
transient simulation are presented. The total power decreases in the null transient because of the initial negative reactivity caused by the non-uniform temperature distribution in the reactor core. The initial negative reactivity is then compensated by the decrease in the fuel temperature, the power of the reactor core stabilizes around 200 s to about $4.784 \mathrm{MW}$, about $4.32 \%$ lower than the assigned total power $(5 \mathrm{MW})$. This difference in the total power is acceptable for this demonstration study. Due to the thermal inertial of the system, the system has not actually reached the final steady state yet at 200s, but the simulation is stopped for limitation in the computational resources. Improvements to the coupling model are necessary for the future analysis.

\subsubsection{Simulation of single heat pipe failure}

This test will simulate the transient behavior of the system with a failure of a single heat pipe near the center of the reactor core. The numbering of the heat pipes and fuel cells near the center of the reactor core is shown in Figure 32. In this simulation, the heat pipe with ID = 1 (HP1) is assumed failed at the start of the transient. The failure is modeled by a sudden drop in the flow rate of the attached micro heat exchanger, which will bring in a sudden drop to the heat removal rate by this heat pipe. Because of the failure of HP1, the temperature of the fuel in this fuel cell (FC1) will increase. In addition, the temperature of fuel in the neighboring fuel cells and the heat removal rate in the neighboring heat pipes will increase accordingly.

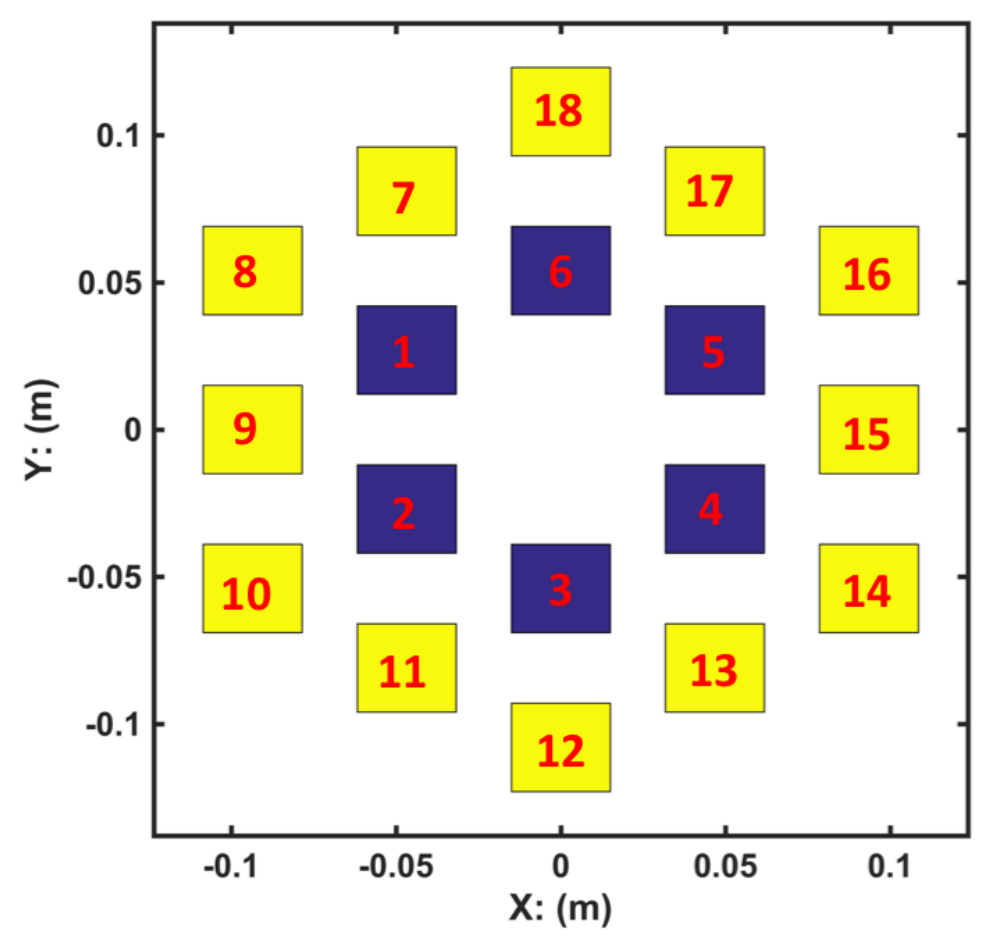

Figure 32 IDs of heat pipes and fuel cells near the center of the reactor core 


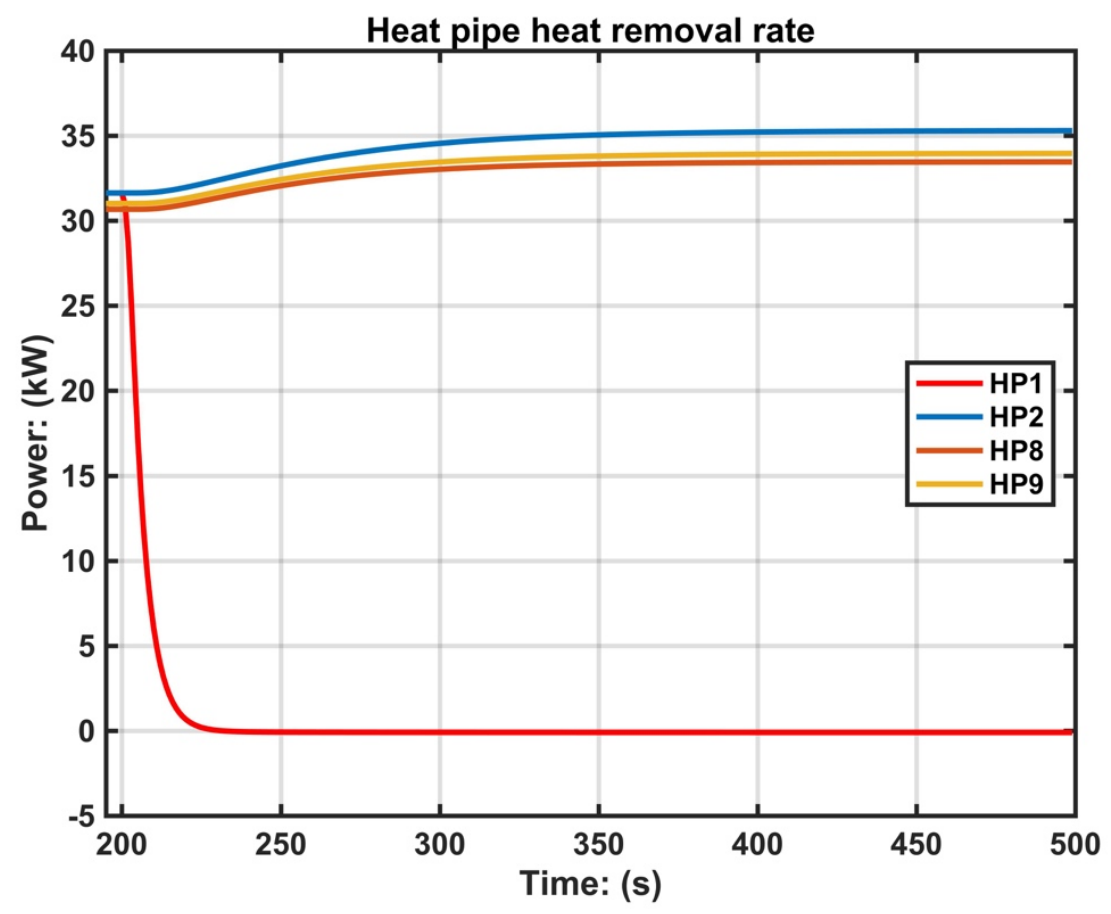

Figure 33 Transient heat pipe heat removal rate in HP1, HP2, HP8, and HP9

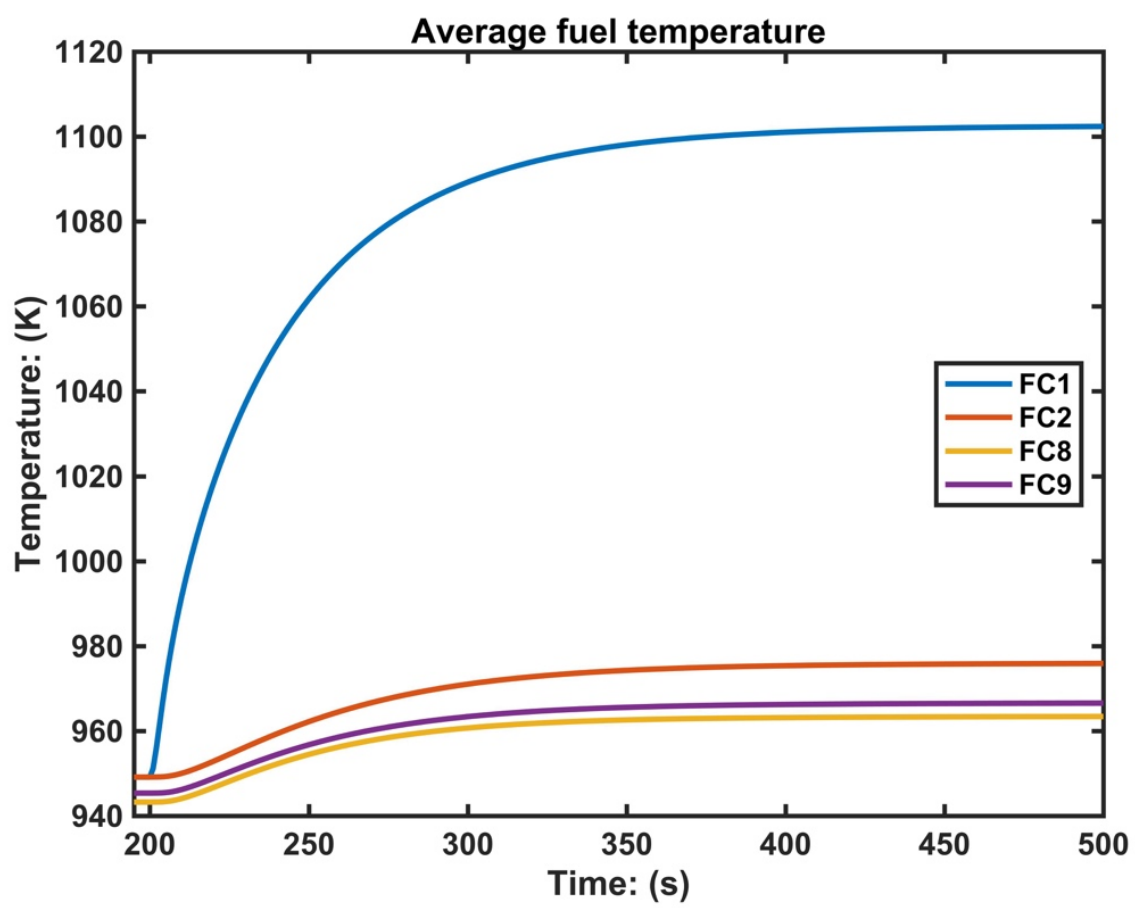

Figure 34 Transient average fuel temperature in FC1, FC2, FC8, and FC9 


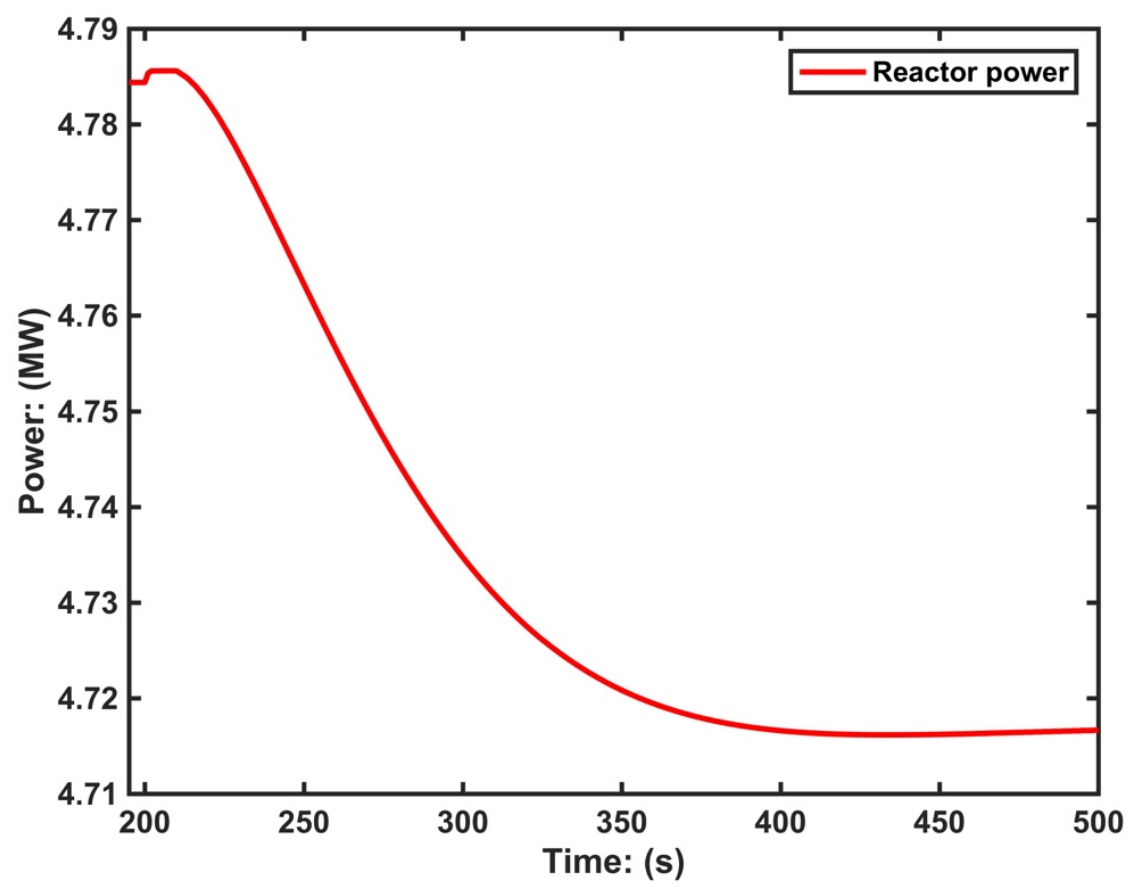

Figure 35 Transient total power with the failure of a single heat pipe
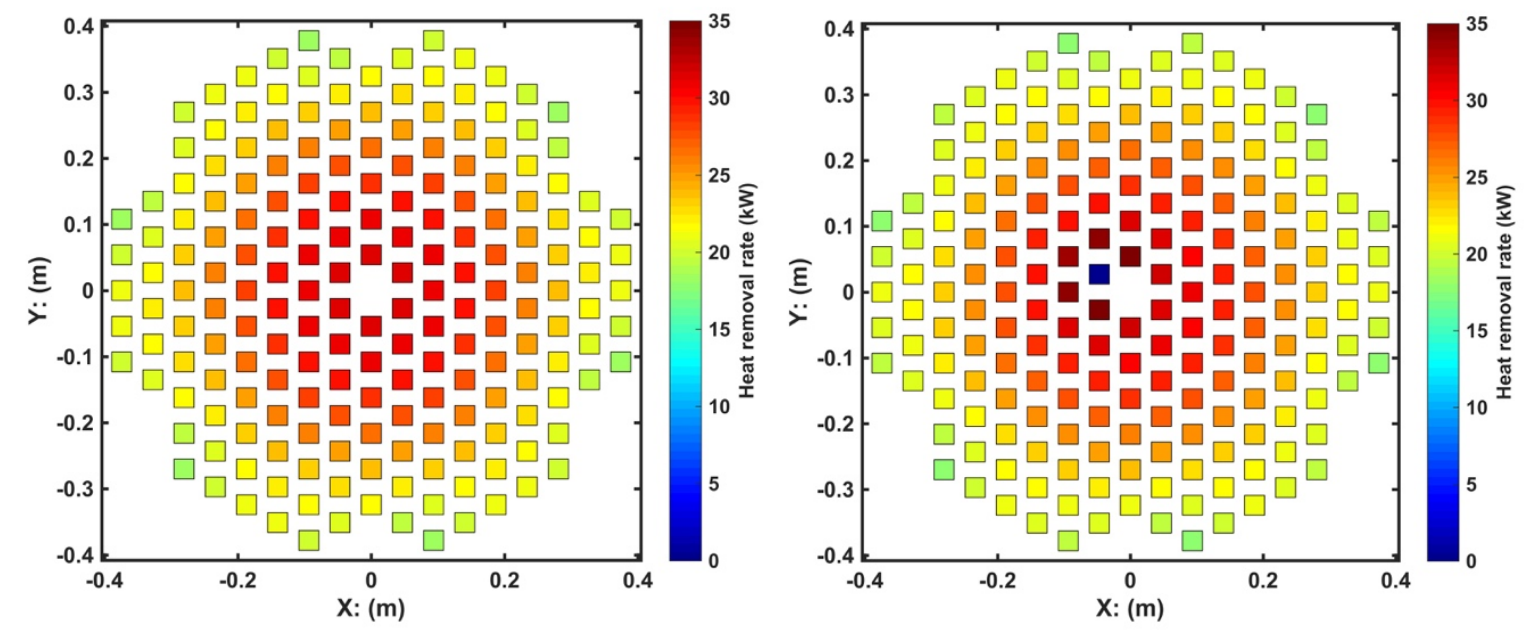

Figure 36 Heat pipe heat removal rate at the start (left, $t=200 \mathrm{~s}$ ) and end (right, $t=500 \mathrm{~s}$ ) of single heat pipe failure transient 

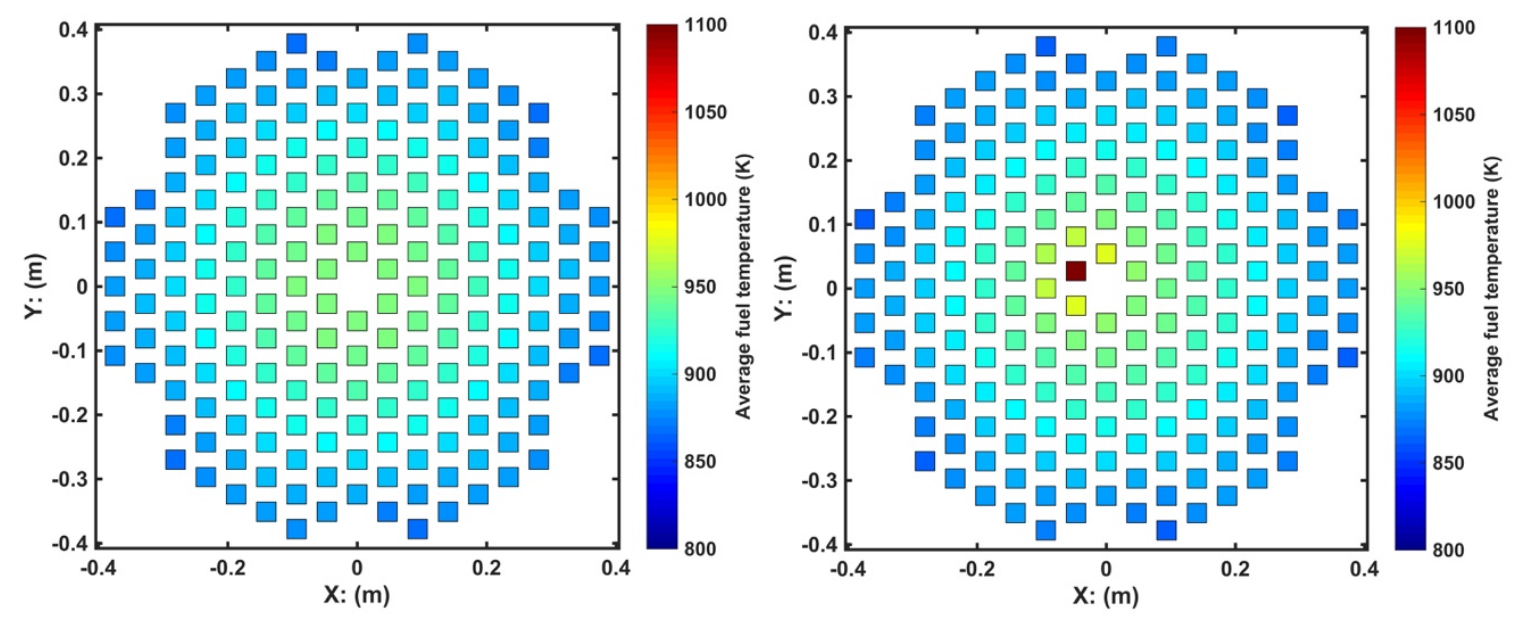

Figure 37 Average fuel temperature at the start (left, $t=200 \mathrm{~s}$ ) and end (right, $t=500 \mathrm{~s}$ ) of single heat pipe failure transient

The simulation is started with a null transient of 200 s and followed by the failure of the HP1. As is shown before, the total power decreases in the null transient because of the initial negative reactivity caused by the non-uniform temperature distribution in the reactor core. The initial negative reactivity is then compensated by the decrease in the fuel temperature, the power of the reactor core stabilizes around 200s. After 200s, HP1 is assumed to be failed.

The single heat pipe failure transient results are shown in Figure 33, Figure 34, Figure 35, Figure 36, and Figure 37. Figure 33 shows the transient heat pipe removal rate in HP1, HP2, HP8, and HP8. Figure 34 shows the average fuel temperature in FC1, FC2, FC8, and FC9. The heat removal rate of HP1 drops to a much lower level, which causes the increase of the average fuel temperature in $\mathrm{FC} 1$. The extra heat in the $\mathrm{FC} 1$ starts being transported to its neighboring fuel cells, which causes the increase of the average fuel temperatures in FC2, FC8, and FC9. The extra heat will be transported out by the neighboring heat pipes, which are observed in the increase of the heat removal rate in HP2, HP8, and HP9. Due to symmetry, only results of 3 neighboring heat pipes and 3 neighboring fuel cells are presented. Figure 35 shows the total power of the reactor. Because of the increase in the fuel temperature, a negative reactivity due to the fuel axial expansion and Doppler effect, the reactor power starts to drop following the single heat pipe failure. However, since the negative reactivity caused by the single heat pipe failure is minor, the reactor power is observed to stabilize to a new lower level at the end of the transient, $500 \mathrm{~s}$ in the current simulation. In addition, Figure 36 shows the distribution of heat pipe heat removal rate at the start and the end of the transient. Figure 37 shows the distribution of the average fuel temperature at the start and end of the transient. The temperature increase in the neighboring fuel cells of the failed HP is very limited $(20 \mathrm{C})$, indicating that there would not be any cascading effects leading to the failure of the neighboring fuel cells.

\subsubsection{Simulation of unprotected loss of heat sink event}

This test simulates the transient behavior of the system with a loss of heat sink (LOHS) event. The loss of heat sink is modeled by a sudden drop in the secondary flow rate (to $0.1 \%$ of nominal condition). Similarly, the simulation is started with a null transient of 200 s and followed by the sudden drop in the secondary flow rate. The transient results are shown in Figure 38, Figure 39, Figure 40, and Figure 41. Figure 38 shows the total reactor power, power to the heat pipes, and the 
power to the RCCS; Figure 39 shows the transient average temperature at different blocks; Figure 40 shows the heat removal rate by individual heat pipes after the transient; Figure 41 shows the average fuel temperature of different fuel cells after the transient.

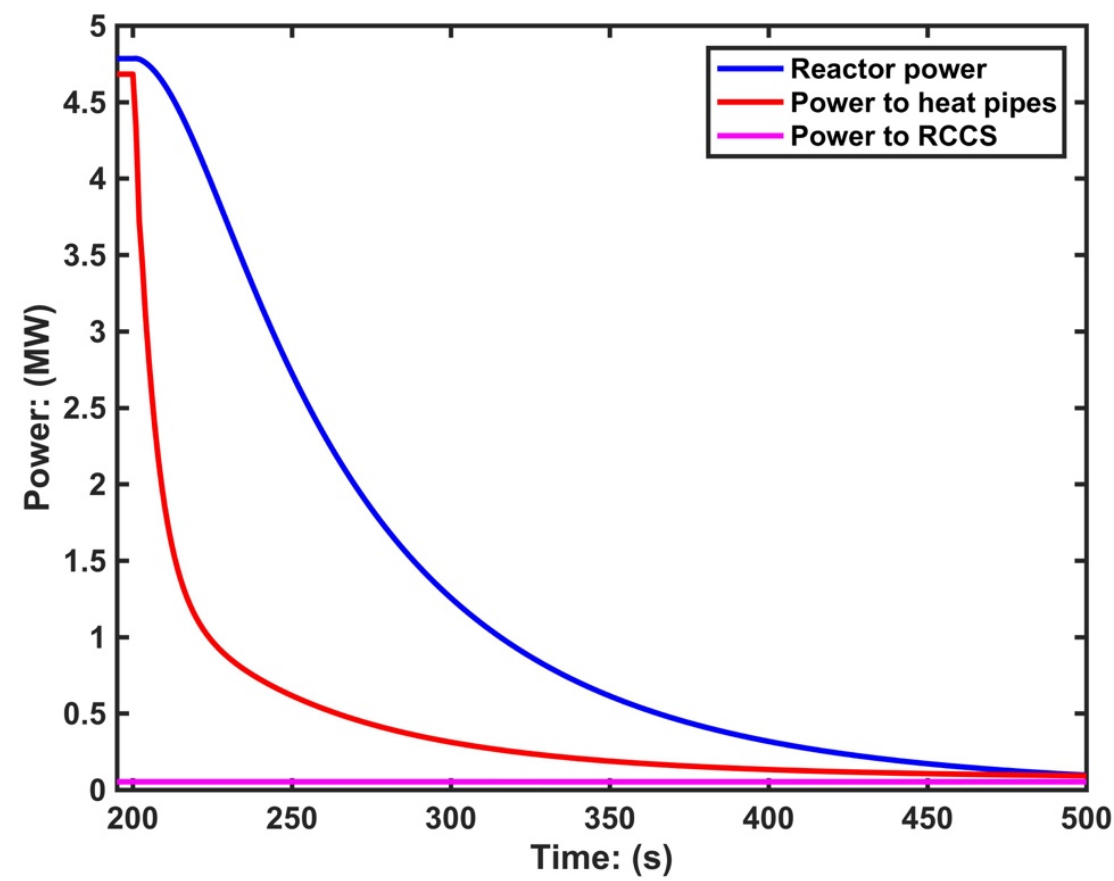

Figure 38 Transient reactor power and heat removal rate

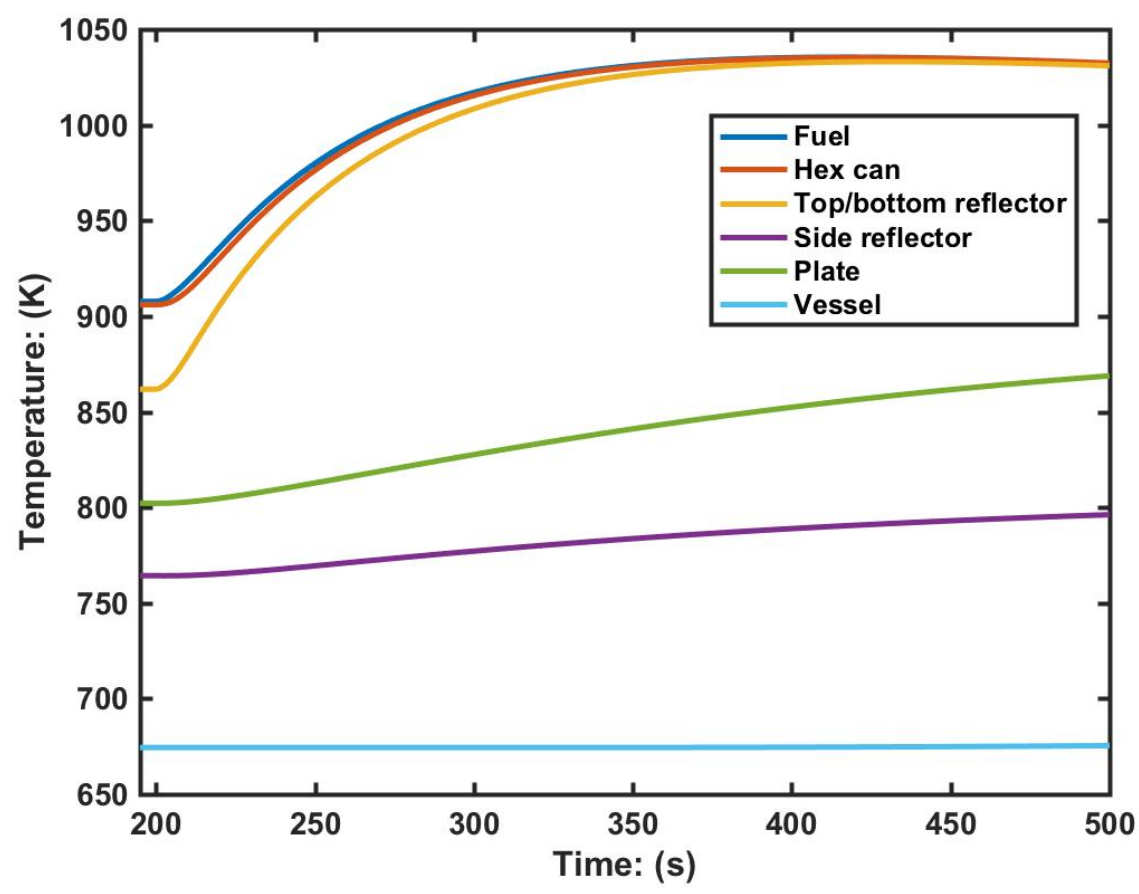

Figure 39 Transient average solid temperature of different blocks 
As discussed above, the power of the reactor core stabilizes around 200s during null transient. After the start of the real transient, the heat transferred to the heat pipes drops quickly to a lower level. As shown in Figure 39, the fuel temperature starts to increase accordingly, which brings in strong negative reactivity to the reactor core, and the reactor power starts to drop. As shown in Figure 40, all heat pipe heat removal rate drops quickly. At the current simulation time, the heat removal rate from the RCCS changes little, as the reactor vessel temperatures increases very slowly, the radiation heat transfer from the vessel outer surface is not important yet. The simulation needs to run for a longer time, which is limited in this report.
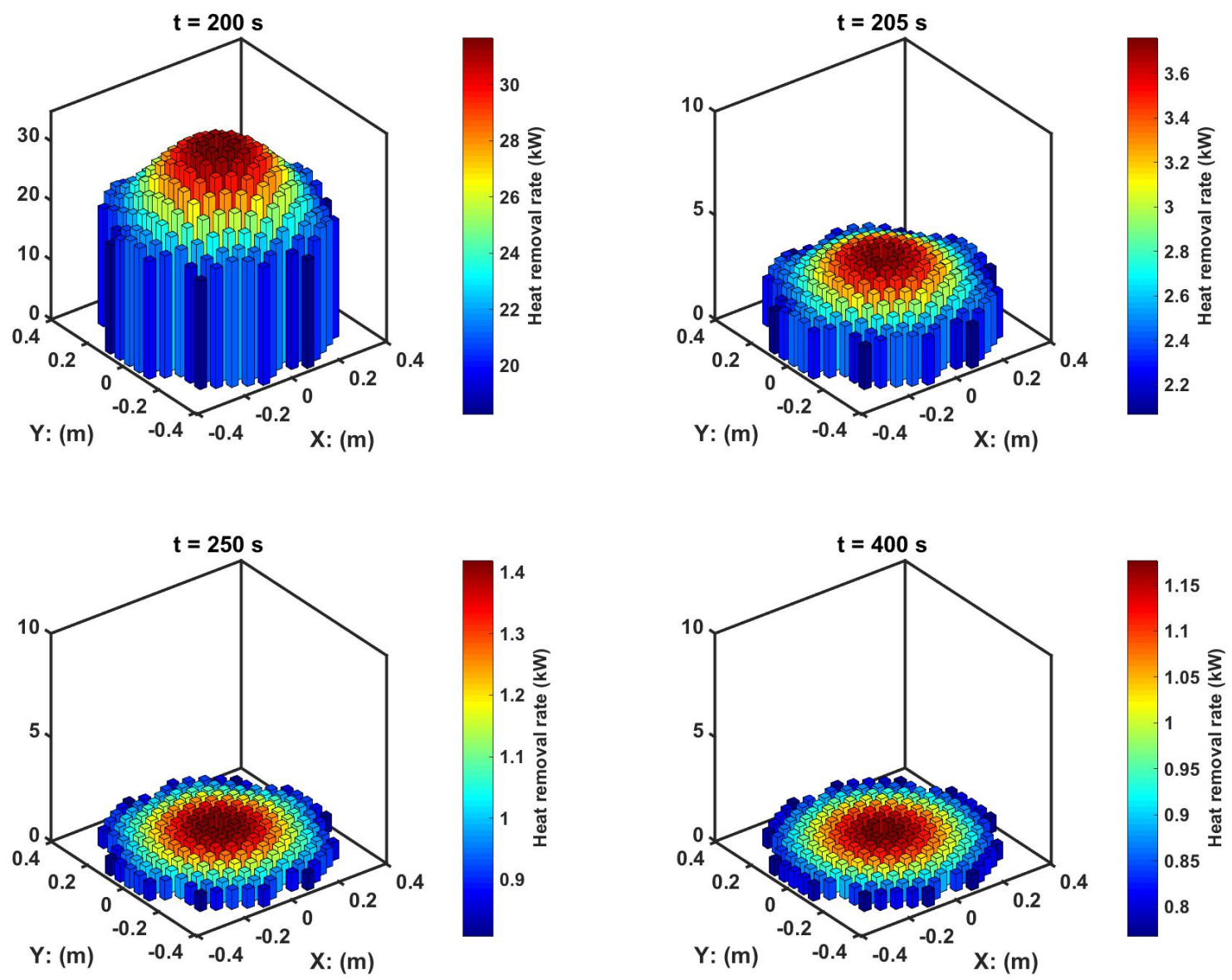

Figure 40 Transient heat pipe removal rate at different time following the loss of heat sink 

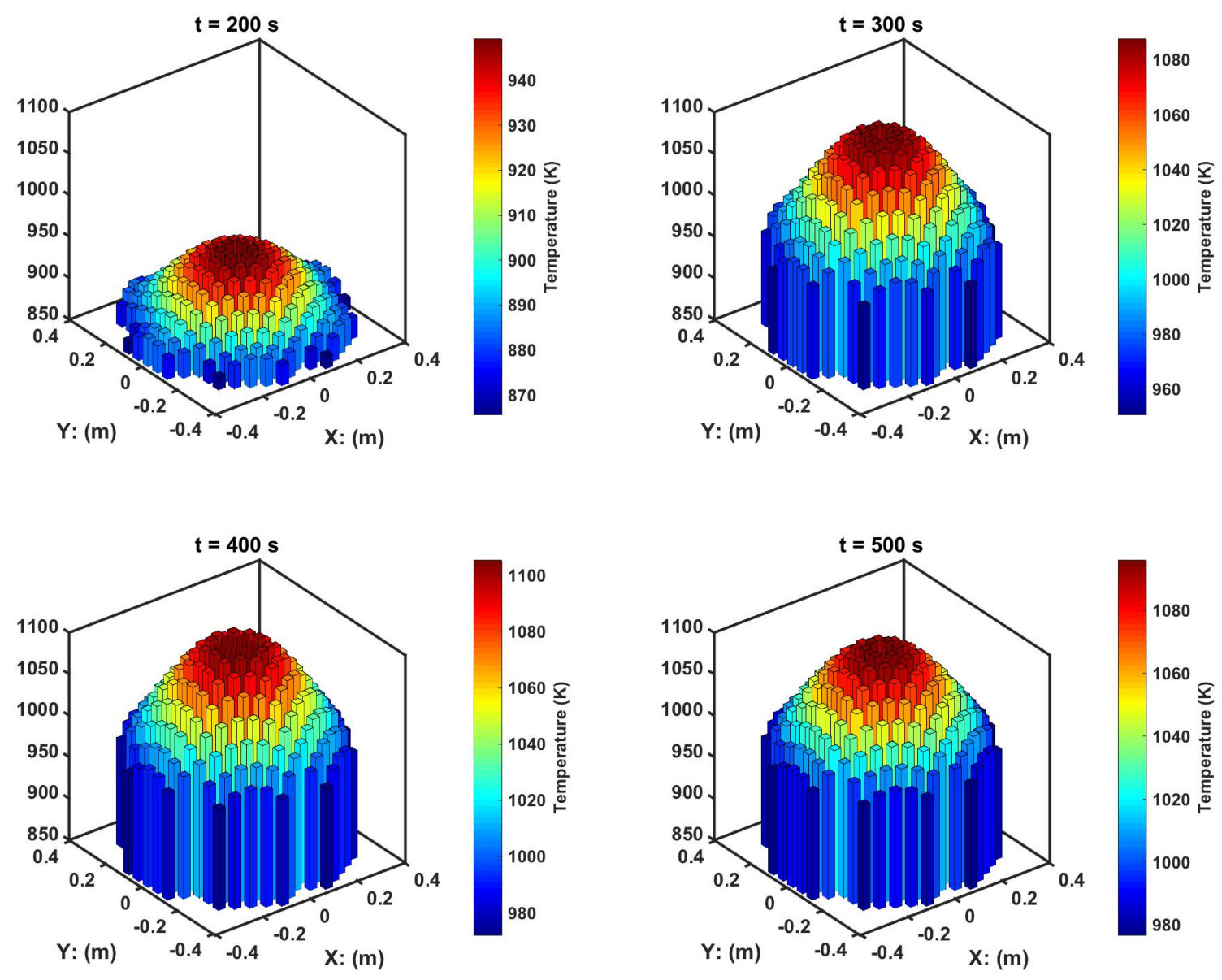

Figure 41 Transient fuel temperature following the loss of heat sink

\subsubsection{Discussion on current issues}

As is noted in previous sub-sections, the current transient simulations are limited to the early stage of the LOHS transient. The following factors causes the limitations and needs to be resolved in the future.

- The RK (reactor kinetics) input model is observed to converges slowly during the transient simulations. During the transient simulation, the main changes are the fuel temperature and the geometry deformation. The nonlinear residual of the RK system remains at a very low level $\left(\sim 10^{-7}\right)$ at the beginning of each time step, the solver has a convergence difficulty. It should be noted that the convergence criterion has to be kept at even lower lever in order to capture the minor reactivity feedback due to the Doppler effect and thermal expansion. The application of using the displaced mesh system for considering the thermal expansion reactivity feedback needs to be improved.

- The HC (core heat conduction) input model is observed to have a convergence difficulty at the later stage of the transient simulation. Currently, the HC model is coupled with the HPs (heat pipe heat exchanger) and the RCCS through MOOSE's MultiApp system. Given the fact that the main change during the transient is the power 
density and the heat removal rate of individual heat pipes, the convergence difficulty is likely caused by the coupling between the HC and HPs. In the future, the coupling between the HC and the HPs needs to be improved to resolve this issue. Currently, Picard iteration between the HC and HPs is used. For the transient simulation, this Picard iteration increases significantly the overall computation time for each time step.

- The current coupled model makes use of the replicated mesh option of the MOOSE system. For a 3D whole core problem like the current model, the required computer memory increases linearly with the number of processors, which limits the total number of processors can be used. It is also observed that the current model does not scale well in a multi-nodes cluster. Currently, various of UserObjects are used extensively in the data transfer between different sub-models, which is found to conflict with the distributed mesh option. In the future, the model needs to be adjusted to make use of the distributed mesh option of MOOSE.

These limiting factors, mixed together, affect significantly the overall computation speed of the coupled simulations. Improvements to the individual sub-modules and the input sub-models are required to simulate the long-term (hours or days) transients. 


\section{Summary and Future Work}

Because of the increasing interests in heat pipe type micro reactors, the capability of SAM has been extended to enable the modeling of the conventional heat pipe and the heat pipe type reactor. In this work, as a submodule of CRAB, the new capability of SAM was demonstrated by performing a whole core fully coupled modeling and simulation of the heat pipe micro reactor.

Three submodules of CRAB, i.e. MAMMOTH, SAM, and MOOSE (Tensor Mechanics Module), and Serpent were used to model the main physical phenomenon in transient analyses of a made-up heat pipe micro reactor. The main phenomenon includes:

- Reactor kinetics: MAMMOTH and Serpent (cross-section preparation)

- 3D Heat transfer in the reactor core: SAM

- Heat pipe heat exchanger: SAM

- Reactor Cavity Cooling System: SAM

- Thermomechanics: Tensor Mechanics

Different sub-models were developed and then coupled together using MOOSE's MultiApp system. The coupled model was used to demonstrate the new capability by performing a steadystate operation analysis, a failure of single heat pipe transient analysis, and a loss of heat sink transient analysis. Using arbitrarily assumed heat pipe reactor design information, the simulation results were seen to be reasonable.

However, it should be noted that the proposed modeling approach have limitations and requires future improvements. Future investigations would include:

- In this new modeling approach, the reactivity feedback due to thermal expansion was considered using the displaced mesh system. This new approach needs future verification effort when non-uniform temperature and expansion are expected in the reactor core.

- In the current work, the cross-section preparation was performed based on the undeformed geometry and the assumption of a uniform fuel temperature. This needs to be adjusted to consider the extra reactivity feedback due to thermal expansion and nonuniform fuel temperature. Iterations between the cross-section preparation and the fully coupled steady state eigenvalue calculation may be required.

- The current transient analysis was stopped at an early stage of the transient, when the reactor power is still high and the role of RCCS system has not become important. The main factor that put this limitation is the rather expensive 3D whole core simulations, e.g. reactor kinetics simulation using the displaced mesh system, 3D thermal expansion simulation, 3D heat conduction in the reactor core, and the Picard iteration between the $3 \mathrm{D}$ heat conduction, heat pipe heat exchangers, and RCCS.

- The secondary heat exchanger and the RCCS were modeled in a rather simplified way. Future effort is necessary in order to be consistent with the feature of the realistic secondary heat exchanger and the actual modeling of the natural circulation flow in RCCS. 
- An efficient and user-friendly way to include the thermal resistances between fuel element hex cans is necessary.

In addition, several verification gaps need being filled in the future:

- Verification of the conjugate heat transfer between the 3D reactor core and the heat pipes using the MOOSE MultiApp system;

- Verification of the radiation heat transfer between the 3D reactor vessel and the RCCS loop using the MOOSE MultiApp system.

Regardless of these limitations and gaps, it should also be noted that the primary goal of the current work was to develop the multi-physics modeling capability for analysis of the heat pipe micro reactor system, which has been demonstrated in this report. 


\section{Acknowledgement}

This report was prepared as an account of work sponsored by an agency of the U.S. Government. Neither the U.S. Government nor any agency thereof, nor any of their employees, makes any warranty, expressed or implied, or assumes any legal liability or responsibility for any third party's use, or the results of such use, of any information, apparatus, product, or process disclosed in this report, or represents that its use by such third party would not infringe privately owned rights. The views expressed in this paper are not necessarily those of the U.S. Nuclear Regulatory Commission.

The conduct of this effort to develop a fully coupled multi-physics reference plant model for a heat pipe cooled micro-reactor was greatly aided by inputs from the Idaho National Laboratory's MAMMOTH and MOOSE development teams, specifically: Vincent Labouré, Sebastian Schunert, Yaqi Wang, Derek Gaston, Cody Permann; and by inputs from Ling Zou of Argonne's SAM development team.

In addition, this research made use of the resources of the High Performance Computing Center at Idaho National Laboratory, which is supported by the Office of Nuclear Energy of the U.S. Department of Energy and the Nuclear Science User Facilities under Contract No. DE-AC0705 ID 14517.

\section{Reference}

[1] Hu, R., SAM Theory Manual, Nuclear Engineering Division, Argonne National Laboratory, ANL/NE-17/4, Argonne, IL, March, 2017.

[2] Hu, R., Zou, L., Hu, G., 2019a, SAM User's Guide, Argonne National Laboratory, ANL/NSE-19/18, Argonne, IL, August 2019.

[3] Gaston, D., Newman, C., Hansen, G., Lebrun-Grandi’E, D., MOOSE: A Parallel Computational Framework for Coupled Systems of Nonlinear Equations, Nuclear Engineering and Design, 239, p. 1768-1778, 2009.

[4] Balay, S., et al, PETSc Users Manual: Revision 3.10. No. ANL-95/11 Rev 3.10. Argonne National Laboratory, 2018.

[5] Faghri, Amir. Heat pipe science and technology. Global Digital Press, 1995.

[6] Hu. G., Hu, R., and Zou, L., 2019b, Development of Heat Pipe Reactor Modeling in $S A M$, Nuclear Science and Engineering Division, Argonne National Laboratory, ANL/NSE-19/9, 2019

[7] $\mathrm{Ku}, \mathrm{J} .$, Introduction to heat pipes, Thermal and Fluid Analysis Workshop, 2015

[8] Lee, Ho Sung. Thermal design: heat sinks, thermoelectrics, heat pipes, compact heat exchangers, and solar cells. John Wiley \& Sons, 2010.

[9] Dincer, Ibrahim, and Mehmet Kanoglu. Refrigeration systems and applications. Vol. 2. New York: Wiley, 2010.

[10] Fink, J. K., and L. Leibowitz. Thermodynamic and transport properties of sodium liquid and vapor. No. ANL--RE-95/2. Argonne National Laboratory, 1995 
[11] McClure, P.R., et al, Design of Megawatt Power Level Heat Pipe Reactors, Los Alamos National Laboratory, LA-UR-15-28840, Los Alamos, NM, November 2015.

[12] Sterbentz, J.W., et al, Preliminary Assessment of Two Alternative Core Design Concepts for the Special Purpose Reactor, Nuclear Science and Technology Div., Idaho National Laboratory, INL/EXT-17-43212, Rev. 1, Idaho Falls, ID, May 2018.

[13] Dickinson, T.J., Performance Analysis of a Liquid Metal Heat Pipe Space Shuttle Experiment, Thesis, Air Force Institute of Technology, AFIT/GAE/ENY/96D-2, December 1996.

[14] Gaston, D. et al, Physics-based multiscale coupling for full core nuclear reactor simulation, Annals of Nuclear Energy 84 (2015), pp. 45-54.

[15] Wang, Y., Nonlinear Diffusion Acceleration for the Multigroup Transport Equation Discretized with SN and Continuous FEM with Rattlesnake. In: Proceedings to the International Conference on Mathematics, Computational Methods \& Reactor Physics (M\&C 2013). Sun Valley, Idaho, USA, May 2013.

[16] Wang Y., Schunert S., Ortensi J., Gleicher F. N., Baker B. A., DeHart M., Martineau R. C., Demonstration of MAMMOTH Fully-Coupled Multiphysics Simulation with the Godiva Benchmark Problem, 2017 International Conference on Mathematics and Computational Methods Applied to Nuclear Science and Technology, Jeju, Korea, April 16-20, 2017.

[17] Williamson, R. et al, Multidimensional Multi-physics Simulation of Nuclear Fuel Behavior. Jou. Nucl. Mat. 423.149-163 (2012).

[18] Hebert, A., Mathonniere, G., Development of a third generation superhomogenization method for the homogenization of pressurized water reactor assembly. Nuc. Sci. Eng. 2 (1993), p. 115.

[19] Ortensi, J. et al, A Newton solution for the Superhomogenization method: The PJFNKSPH. Annals of Nuclear Energy 111 (Jan. 2018), pp. 579-594.

[20] Laboure, V. et al, Hybrid Super Homogenization and Discontinuity Factor Method for Continuous Finite Element Diffusion. Submitted to Annals of Nuclear Energy (2018).

[21] Leppanen, J., Development of a New Monte Carlo Reactor Physics Code. PhD thesis. Helsinki University of Technology, 2007.

[22] Novak, A. et al., Pronghorn Theory Manual. Tech. rep. INL/EXT-18-44453. Idaho National Laboratory, 2018.

[23] Zou, L. et al, Stabilized finite element formulation for thermally-driven porous media flows in Pronghorn. ANS Annual Summer Meeting 2018, Driving the Future of Nuclear Technology. ANS. Philadelphia, PA, 2018.

[24] Cai, L., Condensation and homogenization of cross sections for the deterministic transport codes with Monte Carlo method: Application to the GEN IV fast neutron reactors. Université Paris Sud - Paris XI, 2014. English. 


\section{Argonne}

Nuclear Science and Engineering Division

Argonne National Laboratory

9700 South Cass Avenue, Bldg. 208

Argonne, IL 60439

www.anl.gov 